\title{
The Lactate Minimum Test: Concept, Methodological Aspects and Insights for Future Investigations in Human and Animal Models
}

\author{
Leonardo H. D. Messias ${ }^{1}$, Claudio A. Gobatto ${ }^{1}$, Wladimir R. Beck ${ }^{2}$ and \\ Fúlvia B. Manchado-Gobatto ${ }^{1 *}$
}

'School of Applied Sciences, University of Campinas, Sao Paulo, Brazil, ${ }^{2}$ Department of Physiological Sciences, Biological and Health Sciences Center, Federal University of São Carlos, São Paulo, Brazil

OPEN ACCESS

Edited by:

Robert Aughey,

Victoria University, Australia

Reviewed by:

Stefanos Volianitis,

Aalborg University, Denmark

Fabio Rubens Serpiello,

Victoria University, Australia

*Correspondence:

Fúlvia B. Manchado-Gobatto

fulvia.gobatto@fca.unicamp.br

Specialty section:

This article was submitted to

Exercise Physiology

a section of the journal

Frontiers in Physiology

Received: 15 March 2017

Accepted: 24 May 2017

Published: 08 June 2017

Citation:

Messias LHD, Gobatto CA, Beck WR and Manchado-Gobatto FB (2017) The Lactate Minimum Test: Concept, Methodological Aspects and Insights for Future Investigations in Human and Animal Models. Front. Physiol. 8:389.

doi: 10.3389/fphys.2017.00389
In 1993, Uwe Tegtbur proposed a useful physiological protocol named the lactate minimum test (LMT). This test consists of three distinct phases. Firstly, subjects must perform high intensity efforts to induce hyperlactatemia (phase 1). Subsequently, 8 min of recovery are allowed for transposition of lactate from myocytes (for instance) to the bloodstream (phase 2). Right after the recovery, subjects are submitted to an incremental test until exhaustion (phase 3). The blood lactate concentration is expected to fall during the first stages of the incremental test and as the intensity increases in subsequent stages, to rise again forming a " $U$ " shaped blood lactate kinetic. The minimum point of this curve, named the lactate minimum intensity (LMI), provides an estimation of the intensity that represents the balance between the appearance and clearance of arterial blood lactate, known as the maximal lactate steady state intensity (iMLSS). Furthermore, in addition to the iMLSS estimation, studies have also determined anaerobic parameters (e.g., peak, mean, and minimum force/power) during phase 1 and also the maximum oxygen consumption in phase 3; therefore, the LMT is considered a robust physiological protocol. Although, encouraging reports have been published in both human and animal models, there are still some controversies regarding three main factors: (1) the influence of methodological aspects on the LMT parameters; (2) LMT effectiveness for monitoring training effects; and (3) the LMI as a valid iMLSS estimator. Therefore, the aim of this review is to provide a balanced discussion between scientific evidence of the aforementioned issues, and insights for future investigations are suggested. In summary, further analyses is necessary to determine whether these factors are worthy, since the LMT is relevant in several contexts of health sciences.

Keywords: lactate minimum intensity, maximal lactate steady state intensity, anaerobic threshold, individualized exercise prescription, protocol validity

\section{INTRODUCTION}

The important role of individualized exercise intensity has been accepted worldwide in several areas of the health sciences. These include athlete's performance improvements (Jones and Carter, 2000; Bosquet et al., 2002; Bentley et al., 2007), non-athletes' health (Mendes et al., 2015; Parmenter et al., 2015) and also patients with cancer, cardiovascular disease, diabetes and other diseases, 
in order to improve their clinical status and quality of life (Wasserman and McIlroy, 1964; Paffenbarger and Hyde, 1984; Klika et al., 2009; Kirkham et al., 2013; O’Hagan et al., 2013; Scharhag-Rosenberger et al., 2015). Irrespective of the context in which exercise and its individualized intensity prescription are used, researchers constantly focus on the accurate determination of variables used to prescribe the exercise intensity. In this sense, the search for tests or protocols that provide reliable and reproducible results is a key factor for training effectiveness, including its prescription, and exercise control.

Physiological parameters such as the percentage of maximal heart rate $\left(\mathrm{HR}_{\max }\right)$ (Karvonen and Vuorimaa, 1988), maximal oxygen consumption $\left(\mathrm{VO}_{2 \max }\right)$ (Poole and Richardson, 1997) and metabolic markers like the blood lactate concentration ([Lac]) (Billat, 1996) have been extensively used for individualized exercise prescription. Although, the prescription of relative or absolute intensities has demonstrated high applicability for many populations, criticism exists around the physiological tests or protocols used to assess cardiovascular, respiratory, and metabolic variables. Due to these criticisms, exercise physiologists requested new tests or studies and improvements to tests that have been already proposed.

In this way Uwe Tegtbur, professor and researcher at Hannover Medical School, proposed the named lactate minimum test (LMT) in the early 90s (Tegtbur et al., 1993). This test begins with high intensity efforts to induce a hyperlactatemia state (phase 1), followed by $8 \mathrm{~min}$ of passive rest (phase 2) and finally, an incremental test initialized with low exercise intensity but high blood lactate concentration (phase 3). During the first incremental stages, the blood lactate concentration is expected to fall into a minimum point and rise again over the following stages. According to Tegtbur et al. (1993) this minimum point named the lactate minimum intensity (LMI), provides an estimation of the intensity that represents the balance between the appearance and clearance of arterial blood lactate, known as the maximal lactate steady state intensity (iMLSS). Apart from the aerobic capacity estimation, studies have also applied anaerobic protocols during the hyperlactatemia phase (Smith et al., 2002; Araujo et al., 2013; Camargo et al., 2013; Messias et al., 2015), allowing the determination of anaerobic indexes, such as peak, mean and minimum force/power. Therefore, in addition to its easy application and objectivity, the LMT is also considered a valid physiological protocol for the assessment of aerobic and anaerobic parameters in just one evaluation session (Messias et al., 2015).

Over the years, the LMT has gained popularity around the world, and its application has been seen in several contexts including studies with diabetes (de Oliveira et al., 2007; Oliveira et al., 2010), thrombocytosis (Beck et al., 2014b) and wheelchair-racing athletes (Perret et al., 2012). Despite the fact that important concerns were arisen so far, some questions remain requiring discussion. Can this test be influenced by methodological aspects related to the hyperlactatemia induction, recovery and incremental exercise? Evidence has drawn opposite conclusions regarding the influence of the hyperlactatemia induction modes on determination of the LMT parameters (Smith et al., 2002; Zagatto et al., 2014). These controversies require a balanced discussion of the topic, since its necessity during the LMT is indispensable (see explanation on the next section). Along with the hyperlactatemia modes, some attention has been given to the recovery type and length during phase 2 (Ribeiro et al., 2009). The mitigating factor around this issue is related to a myriad of recovery manipulation used by studies involving this test. The discussion in this topic is required and overdue since its influence on LMT parameters was demonstrated (Ribeiro et al., 2009). Opposite conclusions are also shown regarding the incremental test initiated with high blood lactate concentration (Carter et al., 1999b; Ribeiro et al., 2003). This topic is of utmost relevance, since the determination of LMT parameters is guided by the blood lactate concentration, which can be affected by the stage's intensity (Bentley et al., 2007) and length (Yoshida, 1984).

Along with the methodological controversies, two other points must be better explored. Is the LMI a valid parameter for monitoring longitudinal training effects? Here, we have a favorable discrepancy regarding the LMI effectiveness (Silva et al., 2007; Miranda et al., 2013; Campos et al., 2014); however, this perspective has hardly been criticized (Carter et al., 1999a) and a balanced discussion around both sides is required. The last and debatable point is related to the relationship between the iMLSS and LMI. Does the LMI indeed estimate the iMLSS? This issue can be considered as one of most studied (Jones and Doust, 1998; MacIntosh et al., 2002; Johnson et al., 2009; Dotan et al., 2011; Knoepfli-Lenzin and Boutellier, 2011), since the MLSS protocol is considered the gold standard protocol for the anaerobic threshold estimation (Heck et al., 1985; Beneke, 1995, 2003; Beneke and von Duvillard, 1996; Beneke et al., 1996, 2000). Additionally, despite the relationship between the iMLSS and LMI is the key aim of the LMT proponents (see next section), there are controversies regarding this issue. Moreover, important methodological concerns were not considered when the comparison between these two intensities was made. These subjects will be discussed in this review.

We have listed questions that still require deep discussion. These points are important for both science and practice and a balanced discussion can help further studies to improve the knowledge around the LMT. Therefore, the main aim of this review is to provide a balanced discussion between studies that are favorable to the LMT with those that criticized this test, especially regarding the listed points that still require investigation. There are four specific objectives of this review: (a) to discuss the possible influence of the hyperlactatemia induction, recovery and incremental test on determination of the LMT parameters; (b) to debate the factors that are impairing the LMI effectiveness for monitoring training effects, especially those applied to improve aerobic parameters (i.e., aerobic power and capacity); (c) to examine studies that compared the LMI with iMLSS and discuss possible factors that still hamper the relationship between these two intensities; and (d) transpose all the discussed perspectives to animal model.

Firstly, a historical perspective about the LMT will be provided. This is necessary to understand how this test was proposed and why its parameters have physiological significance. Then, in the section "Can the LMT be influenced 
by methodological aspects?" the controversies related to the LMT phases will be discussed and insights about future investigations will be provided. The section "Is the LMI modified after training?" refers to controversies regarding the LMI effectiveness for monitoring training effects. We propose an untested hypothesis that relates this issue with a possible mathematical modeling dependency. Subsequently, studies that compared the LMI with iMLSS will be discussed in the section "Does the LMI indeed estimate the iMLSS?" As in the previous section, we propose another untested hypothesis to improve the knowledge around the relationship between these two intensities; this perspective is related to methodological concerns of both protocols, especially in the determination of iMLSS. Lastly, considering this test is not limited to the human model, we included a section that discusses every controversial point highlighted so far in animal models.

Relevant literature was considered by searching PubMed, SPORTDiscuss, Scopus, SCIELO, and Google Scholar databases. Studies were included based on the aims of this review. Therefore, queries comprising combinations of terms such as "lactate minimum test," "hyperlactatemia," "recovery," "incremental test," "methodological aspects," "training," "lactate minimum intensity," "anaerobic threshold," and "maximal lactate steady state intensity" were considered. We also accessed studies referenced by any of the already published papers. English language studies were included in this review without any restriction on publication date. Sample characteristics, reproducibility of the results showed in the cited studies and the numbers of participants evaluated were not limiting factors and did not determine the study inclusion. The standardized mean difference (SMD) between the results of the studies was calculated to provide practical inferences and support the study conclusions. The comparison of data from two groups was performed using SMD = (first group mean data-second group mean data) / standard deviation average from both groups. When studies compared more than two groups, the SMD was calculated as $\mathrm{SMD}=$ (highest mean data-lowest mean data) / square root of the mean square error.

\section{THEORETICAL CONCEPT OF THE LMT}

In the field of exercise physiology, it is necessary to understand which factors allow the body to continue exercising. In the first chapter of his book, Mosso (1904) provides an interesting discussion about the migration of birds and how the "fatigue signals" are evident over their journey, mainly when they arrive to the desired location. In isolated muscles, research published at the beginning of the twentieth century showed that the lactic acid, previously discovered in 1780 in sour milk by Carl Wilhelm Scheele, is also produced during muscle metabolic processes (for complete historical background see Gladden, 2008). In 1923, an article by Hill and Lupton entitled "Muscular exercise, lactic acid, and the supply and utilization of oxygen" was the first published work to suggest that lactic acid reflects the exercise intensity, and its production is dependent upon the muscle oxygen supply (Hill and Lupton, 1923).
Even with fewer technological possibilities, Hill and Lupton importantly stated that lactic acid production does not solely occur in the oxygen absence, but there is also a balance between its production and removal at rest (Hill and Lupton, 1923). The possibility that a "physiological steady state" exists in some exercise intensities and that this steady state may be estimated by the lactate concentration in the blood stream were novel insights. Ten years later, Margaria et al. (1933) suggested, based on several experiments of high intensity exercises (i.e., 4-10 min), that blood lactate accumulation was not temporally associated with the post-exercise oxygen consumption, proposing the term "alactacid." Despite this novel finding, it is clear that in Margaria's article the steady state was already considered an important phenomenon. These authors precisely stated that in exercise ( $\sim 10 \mathrm{~min})$ not involving the maximum metabolic rate, there is a balance between the lactate production and diffusion from muscles into the blood stream, and the diffusion from the blood stream to tissues that are not producing lactate.

It is valid to state that authors have challenged the postexercise oxygen debt theory (Gaesser and Brooks, 1984; Brooks, 1985). Apart from the controversies, the fact is that several studies contributed significantly to the understanding of possible mechanisms of the steady state phenomenon in exercise (Bang, 1936; Wasserman and McIlroy, 1964; Kindermann et al., 1979; Sjodin and Jacobs, 1981; Stegmann et al., 1981; Heck et al., 1985; Mader and Heck, 1986; Gobatto et al., 2001). For instance, the hyperbolic power-time relationship from the critical power concept (Monod and Scherrer, 1965) aims to determine the highest intensity that may be sustained for a long time without fatigue (for revision see Jones et al., 2010). The point of optimal respiratory efficiency (Hollmann, 1959), onset of blood lactate accumulation (Sjodin and Jacobs, 1981) and the so called thresholds concepts (Wasserman and McIlroy, 1964; Kindermann et al., 1979) were also proposed with basis in the steady state phenomenon. Regarding the thresholds concepts, Wasserman and McIlroy (1964) proposed that during an incremental cycle ergometer exercise an "anaerobic threshold" may be detected based on the respiratory gas exchange ratio (i.e., the ratio between $\mathrm{CO}_{2}$ production to $\mathrm{O}_{2}$ consumption). The anaerobic threshold detection was originally proposed to avoid exhaustive and potentially dangerous exercise for cardiac patients. According to these authors, this phenomenon is defined as the onset of significant anaerobic metabolism during exercise.

Conversely, Kindermann et al. (1979) challenged the concept based on a second exponential rise of the blood lactate concentration during the latter stages of an incremental treadmill exercise. Then, the former concept stated by Wasserman and McIlroy (1964) proposed the first elevation of blood lactate $\left(\sim 2\right.$ mmol. $\left.\mathrm{l}^{-1}\right)$ concomitantly with a non-linear increase of the ventilation and respiratory quotient, named the "aerobic threshold" (AT). On the other hand, the anaerobic threshold $\left(\mathrm{AT}_{2}\right)$ was considered the steep part of the exponential rise in blood lactate. The anaerobic threshold concept (i.e., $\mathrm{AT}_{2}$ ) will be used throughout this review.

Considering the great utilization of incremental tests for AT determination, Davis and Gass (1979) importantly showed whether the blood lactate is elevated prior to the incremental 
exercise the lactate kinetic is affected. It is clear from Davis and Gass (1979) study that there is a difference in the blood lactate curve during the incremental test of Test 3 . Since the lactate concentration reduction in Test 3 occurred at levels far above the AT determined in Tests 1 and 2, Davis and Gass (1979) confirmed the $\mathrm{AT}_{2}$ concept at the point in which the blood lactate concentration increased significantly in the latter test. According to these authors, the range between $\mathrm{AT}$ and $\mathrm{AT}_{2}$ predicts a steady state work intensity. Another interesting fact was that in every test the blood lactate concentration increased at $\sim 260$ W. In fact, this increase was expected, since its production and clearance are unbalanced at intensities above the $\mathrm{AT}_{2}$. However, considering that in Test 3 the subjects began the incremental exercise with a high blood lactate concentration, the blood lactate firstly decreased at the 6th min into a minimum point, and then increased again until the test ended.

Fourteen years after the Davis and Gass article, Tegtbur et al. (1993) turned their attention to the "minimum point." The first working hypothesis of these authors was that the minimum point would represent a maximal intensity where the blood lactate production and catabolism are in balance, which is the iMLSS. Additionally, by relying on Poole's study (Poole et al., 1988), these authors proposed the second working hypothesis, which was that the minimum point would correspond to the power asymptote (Moritani et al., 1981) from the power-time relationship (Monod and Scherrer, 1965).

To test these hypotheses, endurance-trained runners (ER) and less endurance trained basketball players (BB) were evaluated on a $200 \mathrm{~m}$ indoor track under the same method. The LMT was then proposed using three phases: (1) an initial lactic acidosis induction phase (i.e., hyperlactatemia phase) based on two exhaustive efforts of 300 and $200 \mathrm{~m}$ for ER, or $2 \times 200 \mathrm{~m}$ for $\mathrm{BB}$ with $1 \mathrm{~min}$ recovery; (2) an $8 \mathrm{~min}$ recovery allowing the lactate to diffuse from the muscles to the blood stream; and (3) an incremental test with an initial speed ranging from 3.00 to 4.33 $\mathrm{m} . \mathrm{s}^{-1}$, with increases in the running speed by $0.33 \mathrm{~m} . \mathrm{s}^{-1}$ every $800 \mathrm{~m}$ until exhaustion.

It is possible to notice from the study of Tegtbur et al. (1993) the "U" shaped form of the blood lactate concentration during the incremental test. As previously noted the blood lactate concentration is expected to fall into a minimum point and then rise again until exhaustion due to the low intensity of the first incremental stages. The lactate minimum speed (LMS; i.e., LMI in terms of running exercise) was considered to be the intensity ( $x$ axis-vertical line) related to the minimum point in the " $U$ " shaped curve and, according to the authors, identified by a spline function. Considering the first hypothesis, the LMS should represent an intensity in which the blood lactate production and catabolism are in balance.

Aiming to test this hypothesis, the subjects completed two $8 \mathrm{~km}$ constant load runs at the LMS and at $0.2 \mathrm{~m} . \mathrm{s}^{-1}$ above the LMS. The authors showed that only a $0.2 \mathrm{~m} . \mathrm{s}^{-1}$ increase in the LMS also resulted in a significant increase of $1.9 \pm 1.1$ mmol. $1^{-1}$ in blood lactate concentration. However, no significant increase was found during the $8 \mathrm{~km}$ run at LMS (i.e., 0.4 $\left.\pm 0.4 \mathrm{mmol} \cdot \mathrm{l}^{-1}\right)$. Despite the fact that the MLSS protocol was not properly applied (i.e., the subjects only ran in two different intensities), the authors accepted the first hypothesis by concluding that the LMS and iMLSS were equal. Moreover, considering that Poole et al. (1988) successfully estimated the iMLSS by using the hyperbolic power-time relationship, Tegtbur and colleagues also accepted the second working hypothesis, even without comparing the asymptote from the power-time relationship and the LMS. Considering these results, the authors proposed the LMT as an easy alternative protocol for estimating the steady state phenomenon during exercise, since the MLSS and the critical power test may take at least 4-5 days and are, therefore, inappropriate for routine use.

Despite this important result, the authors also investigated whether the LMS is a function of the incremental test duration and is also dependent on the muscle glycogen content. Regarding the incremental test duration, it was demonstrated that the LMS would not be changed whether the $800 \mathrm{~m}$ or $1200 \mathrm{~m}$ tests were applied (LMS $=4.49 \pm 0.17 \mathrm{~m} . \mathrm{s}^{-1}$ and $4.44 \pm 0.18$ $\mathrm{m} . \mathrm{s}^{-1}$, respectively). However, high LMS (4.96 $\left.\pm 0.35 \mathrm{~m} . \mathrm{s}^{-1}\right)$ was obtained when $400 \mathrm{~m}$ were used ( 400 vs. $800 \mathrm{~m} P \leq 0.001$; 400 vs. $1,200 P \leq 0.001)$. Thus, the authors suggested that both $800 \mathrm{~m}$ and $1200 \mathrm{~m}$ could be used in the incremental test, but considering practical reasons the $800 \mathrm{~m}$ should be chosen. It was also shown that the muscle glycogen storage did not influence the LMS determination, since a mean difference of 0.00 $\pm 0.09 \mathrm{~m} . \mathrm{s}^{-1}$ was obtained between a group that had 1 day rest plus a carbohydrate-rich diet before the LMT and a group that performed an exhaustive high-intensity run of $80 \mathrm{~min}$ followed by a $24 \mathrm{~h}$ low carbohydrate diet.

After its proposal, the LMT was further recognized as a valid physiological protocol, especially in terms of anaerobic threshold estimation (MacIntosh et al., 2002; Johnson et al., 2009). However, the comparison with other graded exercise tests (GXT; e.g., Balk or Bruce) is unavoidable. The LMT is actually an alternative to estimate the anaerobic threshold and it is difficult to impose huge differences between its application and GXT, since in both cases an incremental test is applied. On the other hand, some LMT advantages can be suggested: (a) the necessity for hyperlactatemia induction permits that other tests such as the Wingate anaerobic test (Bar-Or et al., 1977) or running anaerobic sprint test (Zacharogiannis et al., 2004) might be applied in this phase, allowing the determination of anaerobic indexes (e.g., peak, mean, and minimum power/force). This possibility is not present in applications of GXT; (b) the LMI (e.g., LMS) is individual and it is not associated with fixed blood lactate concentration (Heck et al., 1985); and (c) although mathematical functions (e.g., segmentation of lines along with intersection determination; Hinkley, 1969) were proposed to identify the individual anaerobic threshold during GXT (Stegmann et al., 1981), the LMI identification is easier since the simple visual inspection seems consistent with mathematical functions (e.g., cubic spline of polynomial functions; Ribeiro et al., 2003; Dotan et al., 2011).

Nowadays, the LMT is used in several contexts in which exercise or physiological evaluations are required. For instance, its application was already conducted in a specific manner for taekwondo (Mota et al., 2011), basketball (Araujo et al., 2013; Camargo et al., 2013), table tennis (Barbieri and Gobatto, 2013), 
triathlon (Vicente-Campous et al., 2014), and futsal (Messias et al., 2015; Barbieri et al., 2017) besides several other important issues (Carter et al., 2000; Davison et al., 2000; Dantas De Luca et al., 2003; Zagatto et al., 2004, 2013; Simões et al., 2005; Rotstein et al., 2007; Mezzaroba and Machado, 2013; Miyagi et al., 2015; Sousa et al., 2017). Along with its popularity, concerns have arisen involving the influence of possible methodological aspects on LMT parameters, and effectiveness of LMI for identifying training effects or even iMLSS estimation validity. In the next sections a balanced discussion of these topics will be provided. Additionally, future insights will be suggested in order to improve the scientific knowledge of this test.

\section{CAN THE LMT BE INFLUENCED BY METHODOLOGICAL ASPECTS?}

One of the greatest LMT concerns is the potential influence that the methodological aspects may have on the variables obtained by this test, especially the LMI. As previously noted, the LMT is composed of three phases, making this test potentially dependent on protocol manipulations (Ribeiro et al., 2009). Thus, studies have aimed to investigate whether the hyperlactatemia induction (Smith et al., 2002; Johnson et al., 2009; Zagatto et al., 2014), recovery (Denadai and Higino, 2004; Ribeiro et al., 2009) and the incremental exercise (Carter et al., 1999b; Ribeiro et al., 2003; Sotero et al., 2007; Pardono et al., 2008; Johnson and Sharpe, 2011; Miyagi et al., 2013) may affect the LMI determination (Table 1).

\section{Phase 1: The Role of the Hyperlactatemia Induction}

As previously explained, subjects must initiate phase 3 of the LMT (i.e., incremental test) with high blood lactate concentrations. Therefore, the hyperlactatemia induction in phase 1 is indispensable. This necessity drew the attention of researchers regarding the possible influence that different hyperlactatemia modes may have on the LMT parameters. Smith et al. (2002) were pioneers in this area, showing that LMI determination was not dependent upon the hyperlactatemia induction protocols. Despite this interesting result, the authors pointed out the necessity of considering other methodological aspects rather than creating a hyperlactatemia state, such as the starting intensity and the workload increment in phase 3. Conversely, Zagatto et al. (2014) criticized the Smith's study mainly based on the $1 \mathrm{~min}$ exercise stage used. According to these authors, the $1 \mathrm{~min}$ stage is not sufficient to allow muscle-blood lactate efflux, underestimating the blood lactate concentration to its respective intensity. With a similar approach, Zagatto et al. (2014) proposed the effects of the hyperlactatemia induction protocol on LMI seems to occur when very strong exercises are used.

Studying the LMT phase 1 with a distinct perspective, Johnson et al. (2009) showed that the LMI determination is altered if different muscle groups are used during the hyperlactatemia induction. Active subjects performed two LMTs distinguished by phase 1 , in which a GXT was performed in cycle (test 1 ) or arm-cranking (test 2) ergometers. Phase 3 was not altered and in both cases was applied in the cycle ergometer. The differences that were found regarding the LMI (test 1-168.0 \pm 21.0 ; test $2-157.0 \pm 29.0 \mathrm{~W}$ ) were attributed by the different patterns in terms of lower lactate accumulation and greater oxidation presented in phase 3 by subjects that performed the hyperlactatemia induction in the cycle ergometer. These factors right-shifted the blood lactate kinetics in phase 3 , increasing the LMI. Despite the novelty, these findings did not substantially improve the possible phase 1 influences on LMI determination once the dependence of the AT achievement (which can be extended to the LMI) on the motor pattern of exercise was already found (Beneke and von Duvillard, 1996). Therefore, the difference in terms of LMI shown by Johnson et al. (2009) should be carefully considered, since it does not demonstrate that phase 1 affects the LMI determination, but advocates that specificity regarding the motor pattern should be consistent throughout the LMT phases. Despite the efforts conducted to investigate the influences of hyperlactatemia induction on LMT parameters, investigation of this issue is still required. As Zagatto et al. (2014) have criticized a methodological question in the incremental test used by Smith et al. (2002) (i.e., 1 min stage length), we can highlight other methodological points that are missing in both studies. Firstly, the LMT proponents did not stipulate that the hyperlactatemia induction must result in a certain blood lactate concentration, since subjects may respond individually to the high intensity effort performed in phase 1 . Therefore, subsequent studies can investigate whether this phase results in a peak blood lactate concentration or if it is only necessary to elevate the serum lactate concentration without reaching its peak. Can the peak attainment be dependent on the hyperlactatemia mode? What is the influence of peak blood lactate level attainment on LMT parameter determination? The rationale beyond the aforementioned questions is grounded in the fact that the blood lactate peak concentration was recently proposed to determine the LMI in phase 3 (Miyagi et al., 2013).

To answer these questions, future studies can compare two LMT applications (and its results) in which subjects initiate phase 3 and do or do not attain its blood lactate concentration peak from phase 1 . It is valid to state that the main goal of phase 1 is to achieve the hyperlactatemia state. In this sense, the recovery that is subsequently required on phase 2 may influence the answers from the proposed questions (see next Section). Thus, further studies with the purpose of answering these questions should also consider the methodological concerns of phase 2. These will be discussed in the next subsection.

\section{Phase 2: Active or Passive Recovery? What about the Intensity and Length?}

Another LMT methodological concern lies on the recovery manipulation after the hyperlactatemia induction. Despite the fact that several studies followed the original $8 \mathrm{~min}$ recovery (Bacon and Kern, 1999; Carter et al., 1999a,b, 2000; MacIntosh et al., 2002; Dantas De Luca et al., 2003; Ribeiro et al., 2003; Zagatto et al., 2004, 2013, 2014; Simões et al., 2005, 2009; Hiyane et al., 2006; Altimari et al., 2007, 2010; Azevedo et al., 2007; Silva 


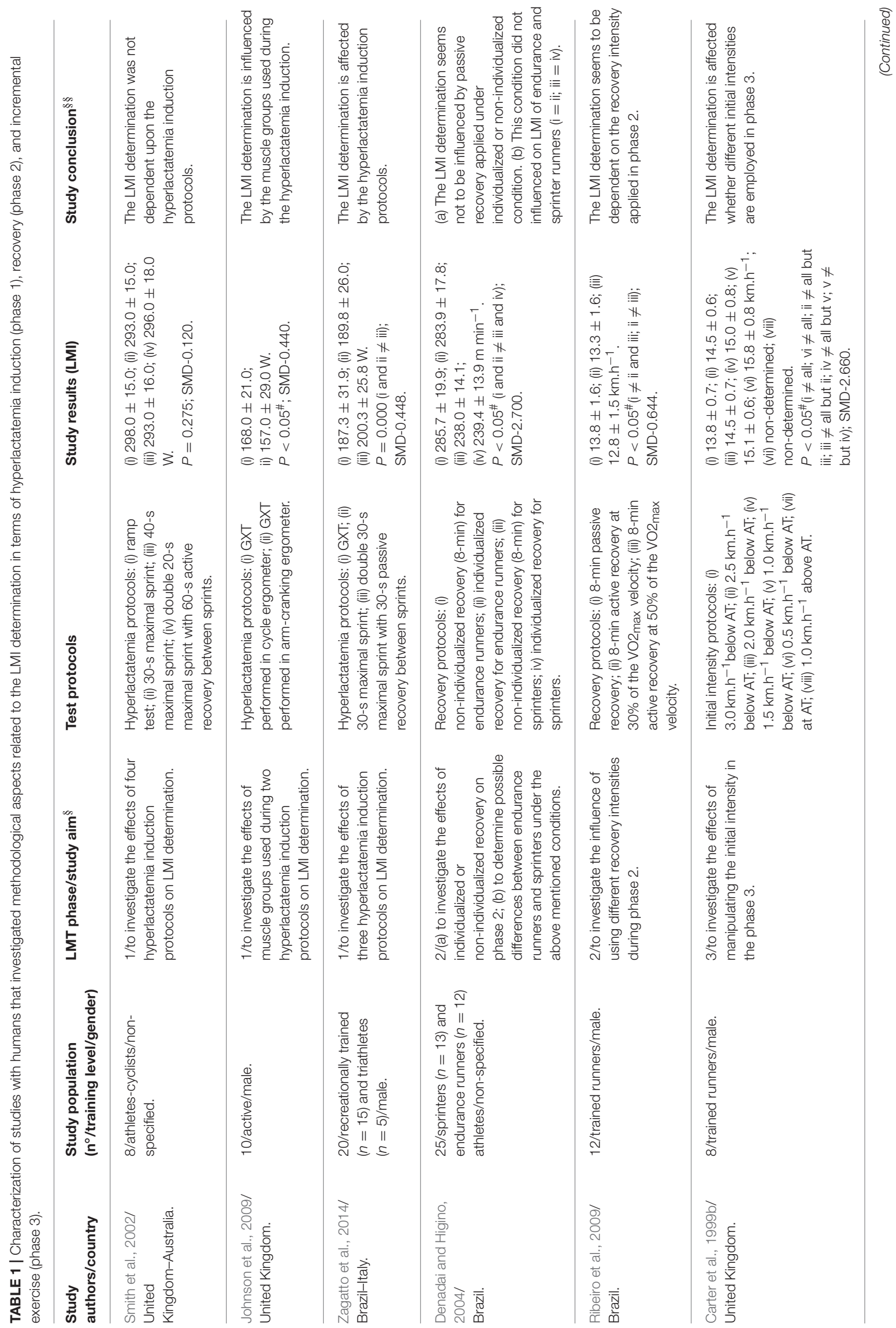




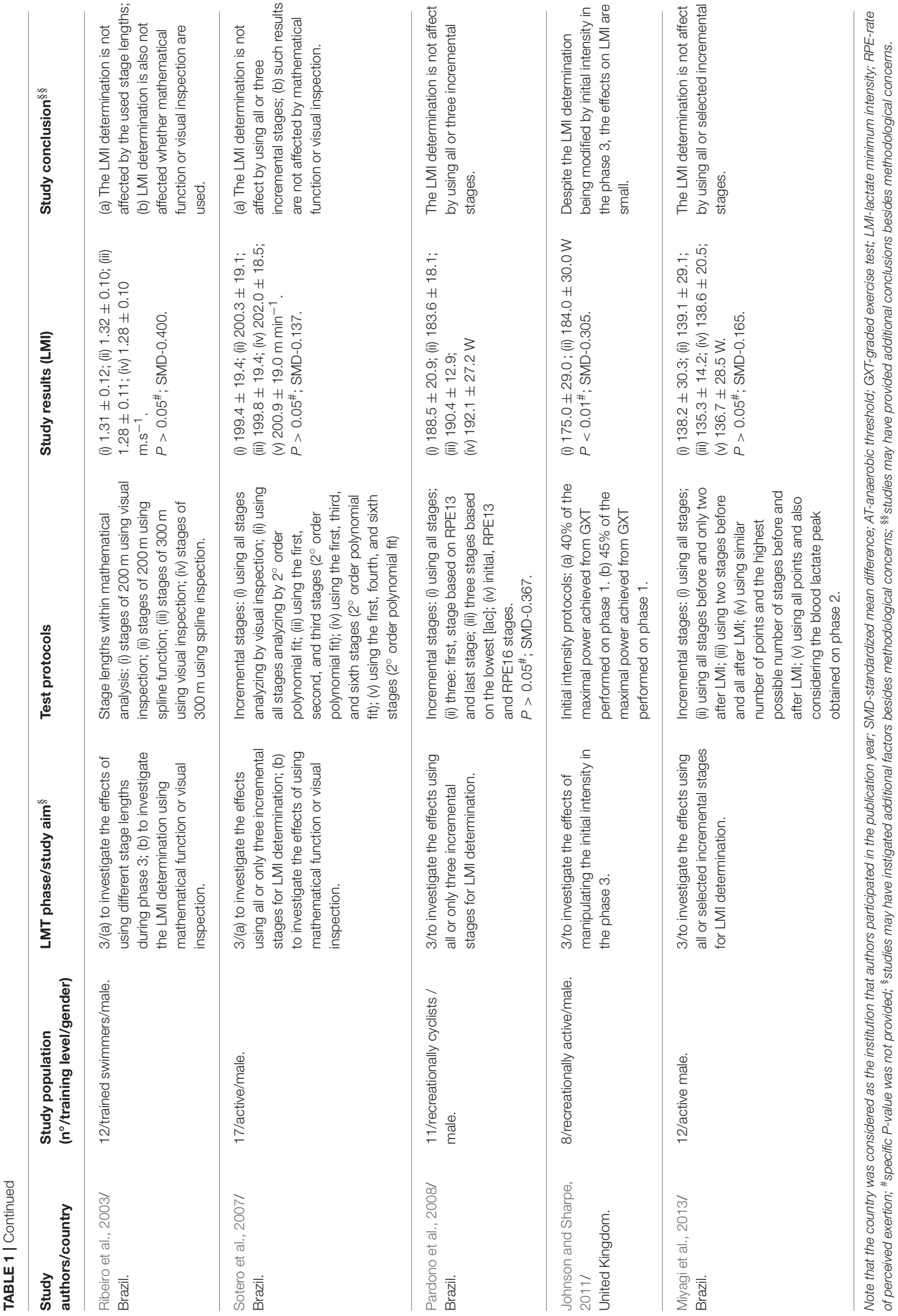


et al., 2007; Pardono et al., 2008; Johnson et al., 2009; Johnson and Sharpe, 2011; Mota et al., 2011; Barbieri and Gobatto, 2013; Camargo et al., 2013; Mezzaroba and Machado, 2013; Miranda et al., 2013; Miyagi et al., 2013, 2015; Campos et al., 2014; Messias et al., 2015), a myriad of recovery manipulations is also observed, especially regarding the recovery type and intensity (Davison et al., 2000; Smith et al., 2002; Rotstein et al., 2007; Silva et al., 2007; Sotero et al., 2007, 2009, 2011; Knoepfli-Lenzin and Boutellier, 2011; Vicente-Campous et al., 2014; Browne et al., 2015). Some attention has been given to this phase due to its potential LMI influence. For instance, Carter et al. (1999b) suggest whether the blood lactate was more quickly removed by an active recovery, then the LMI may be decreased due to a blood lactate concentration left-shift in the second order polynomial fit (i.e., "U" shaped).

Aiming to improve the knowledge on this topic, Ribeiro et al. (2009) submitted trained runners (regional level) to three identical treadmill LMTs, excluding the recovery phase. Confirming the Carter et al. (1999b) hypothesis, a decreased LMI was observed when a stronger active recovery (i.e., iii) was applied $(\mathrm{i}-13.8 \pm 1.6$; ii $-13.3 \pm 1.6$ and iii -12.8 $\pm 1.5 \mathrm{~km} \cdot \mathrm{h}^{-1}$ ). Notwithstanding, the $\mathrm{HR}, \mathrm{VO}_{2}, \% \mathrm{VO}_{2 \max }$ at LMI and the time to achieve the LMI also decreased when the recovery at $50 \%$ of the $\mathrm{VO}_{2 \max }$ velocity was used. These authors point out that the high intensity active recovery accelerates the blood flow and probably increases the metabolic rate of oxidative lactate tissues (e.g., heart and skeletal muscle), resulting in lactate clearance by an intensity-dependent manner. Additionally, Ribeiro et al. (2009) conclude that the LMI among other results seem to be dependent on the recovery adopted, especially when high intensity active recovery is used.

Despite the advances related to the recovery type and intensity, some concerns were not investigated so far, especially in terms of recovery length. The main goal of this phase is to provide sufficient time for the lactate transposition from cells to the bloodstream. However, is the $8 \mathrm{~min}$ recovery proposed by LMT proponents the most appropriate length for this phase? From our point of view and others (Carter et al., 1999b), the $8 \mathrm{~min}$ standardization for all subjects can result in subor super-estimation of the time required for the blood lactate transposition. We again confirm that the " $U$ " shaped form during the LMT is expected, considering subjects will initiate phase 3 with high blood lactate concentration. Subsequently, considering the low intensity of the first incremental stages, the blood lactate is expected to fall into the minimum point and to rise again during the latter incremental stages. However, the " $U$ " shaped form cannot occur if the recovery was beyond (super estimation) or insufficient (sub estimation) when compared to the real subject's necessity. In the super-estimation case, phase 3 can be initiated with low blood lactate concentrations, since the lactate clearance has already occurred during phase 2 . Therefore, the "J" form can be obtained instead of the "U". In the sub-estimation case, subjects can perform the first incremental stages and still result in a high blood lactate concentration, since the given time for phase 2 was not long enough for the lactate transposition; theoretically, in this case, the " $U$ " shape and the minimum point could be right-shifted.
The recovery length can be influenced by aerobic capacity and sports specificity (e.g., endurance or sprinters runners; Carter et al., 1999b; Denadai and Higino, 2004). Literature has demonstrated that lactate clearance is improved in aerobically trained individuals (Donovan and Brooks, 1983) via lactate transporters known as monocarboxylic acid transports (MCTs; Juel and Halestrap, 1999; Halestrap, 2013). High cellular expression and content of MCTs is expected in such individuals (Thomas et al., 2012). Another fact that corroborates the role of MCTs on lactate clearance in trained individuals is the improved lactate utilization as energy is used in tissues or organs that are not directly involved during exercise (Brooks, 1986; Glenn et al., 2015). Therefore, from a biomolecular point of view, the lactate clearance in LMT phase 2 can be influenced by the MCT activity, which is turn, is related to the aerobic capacity. Although, the rationale of these questions seems plausible, the relationship between MCT activity and the blood lactate clearance on phase 2 requires investigation.

Further discussion related to the LMT phase 2 is still required. We have suggested that the $8 \mathrm{~min}$ cannot be adequate for all subjects. However, whether the determination of LMT parameters depends on the recovery length is open for investigation. Evidence has supported that the LMI determination is not a function of standardized or individualized recovery during phase 2 (Denadai and Higino, 2004), but further investigation around this issue was requested. Subsequent studies can examine this question by applying the LMT with a standardized recovery length (i.e., $8 \mathrm{~min}$ ) and an individualized one. The physiological characteristics of subjects must also be accounted for. As previously suggested (Denadai and Higino, 2004), this allows for investigation around several ranges of recovery time, including recovery times shorter than $8 \mathrm{~min}$. In the individualized protocol case, a previous test will be required. During the first evaluation, the same hyperlactatemia mode that will be applied in the LMT must be conducted. Then, by collecting blood lactate samples every $30 \mathrm{~s}$ after the hyperlactatemia induction, researchers may determine the moment in which the blood lactate concentration reaches its peak. This will identify the individual recovery length. Under the same laboratory conditions, the LMT can be applied in the next evaluation section considering this individual length. This design can reveal whether the determination of LMT parameters depends on the recovery length.

\section{Phase 3: Implications on the Incremental Test}

The last concern about the LMT methodology is related to the incremental test (phase 3). Among other evaluations, the incremental test is a valid procedure for determining submaximal and maximal variables. Nonetheless, it is evident in scientific studies that the greatest variation is a result of the type (i.e., stage length and duration) of incremental test used (for review see Bentley et al., 2007). The same variation is also observed in studies involving the LMT application (Bacon and Kern, 1999; Carter et al., 1999a; Davison et al., 2000; MacIntosh et al., 2002; Ribeiro et al., 2003; Johnson and Sharpe, 2011). 
As previously explained, the LMT proponents have already shown concerns about such issues. However, Carter et al. (1999b) criticize the original study by suggesting that the lactate production and its efflux to the bloodstream are intensity and time dependent. In addition, these authors also suggested that the starting incremental test intensity may have an important role in determination of the LMI since the blood lactate kinetics could be directly influenced if different starting intensities are used. Indeed, Tegtbur et al. (1993) applied the initial intensity based on the "individual recovery speed," but these authors did not clarify why this intensity was used.

Aiming to investigate this issue, Carter et al. (1999b) submitted endurance runners to eight similar LMTs except for the incremental starting intensity, which ranged from 3.0 $\mathrm{km} \cdot \mathrm{h}^{-1}$ below the $\mathrm{AT}_{2}$ to $1.0 \mathrm{~km} \cdot \mathrm{h}^{-1}$ above the $\mathrm{AT}_{2}$. These authors demonstrated that the LMI is affected by the starting intensity of the incremental phase, since lower starting intensities resulted in decreased LMI and vice-versa, with the exception of the intensities at the $\mathrm{AT}_{2}$ and $1.0 \mathrm{~km} \cdot \mathrm{h}^{-1}$ above that made it impossible to determine the LMI. These results are partially explained by the fact that at low exercise intensities the lactate removal from the bloodstream is enhanced by visceral organs (e.g., kidney, heart, and liver) and at higher intensities there is cardiac output redistribution away from viscera to supply the blood demand of working muscles. Since the incremental starting intensity directly affects the blood lactate kinetics, the authors conclude that the LMT is an invalid protocol due to its dependency on LMI determination. Even though Carter et al. (1999b) suggested that the LMI determination may also be influenced by the mathematical procedure employed, this topic was not examined. Additionally, the effect of the stage length was also overlooked by these authors.

Four years later, Ribeiro et al. (2003) investigated the effects of both stage length and mathematical procedures on LMI determination. Evaluating trained swimmers (national level), these authors showed that the LMI was not affected by different stage lengths (200 or $300 \mathrm{~m}$ ) or the mathematical procedure employed (visual inspection or spline function), at least for swimming exercises. These results partially corroborate with the original study of Tegtbur et al. (1993), which showed that the LMI is not influenced if $800 \mathrm{~m}$ or $1200 \mathrm{~m}$ distances were applied in the incremental running test. The novelty provided by Ribeiro et al. (2003) lies in the independence of the mathematical procedure employed for LMI determination, since low errors of 0.05 and $0.01 \mathrm{~m} . \mathrm{s}^{-1}$ were obtained when using the visual inspection or spline function, respectively.

Despite the fact that Sotero et al. (2007) raised the LMI determination possibility within reduced blood samples, Pardono et al. (2008) investigated whether less incremental stages or indirect methods could be used for estimating the LMI by polynomial functions in recreational cyclists. These authors showed that the LMI based on the rate of perceived exertion $\left(\mathrm{LMP}_{3 \text { sub }}\right)$ or the three lowest blood lactate stages $\left(\mathrm{LMP}_{3 \mathrm{adj}}\right)$ were not different from the iMLSS $\left(\mathrm{LMP}_{3 \text { sub }}-192.1 \pm 27.2\right.$; $\mathrm{LMP}_{\text {3adj }}-190.4 \pm 12.9$; iMLSS $\left.-204.0 \pm 16.0 \mathrm{~W}\right)$, proposing alternative or shorter forms for LMI determination. The shorter version of the LMT was also studied by Simões et al. (2009), which showed no difference between the LMI determined by visual inspection and several polynomial mathematical functions, including the utilization of only three selected stages and a novel lactate quotient equation (i.e., LMVQ-blood lactate concentration velocity ${ }^{-1}$ ratio plotted against the correspondent velocity). Positive results regarding the LMI determination within less incremental stages were also published by recent investigations (Sotero et al., 2011; Miyagi et al., 2013).

Based on the aforementioned literature, it is clear that efforts were made to analyze methodological concerns in phase 3 . However, future investigations are still required, mainly based on stage length and intensity. These factors can be discussed along with a novel and recent evaluation protocol entitled the reverse lactate threshold (RLT) proposed by Dotan (2012). In this new proposal, the AT is identified in reverse, since after three warm-up stages ( $\sim 4$ min length) with sub AT intensities, a supra AT effort is performed; thereafter, subsequent stages with sub AT intensities are again conducted to identify the highest intensity in which lactate production and clearance are balanced. Although this new proposal is not directly related to the issues of this section, some concerns highlighted during the RLT can be transposed to the LMT application, mainly regarding the stage length and intensity.

Dotan (2012) claims that $<3$ min duration stages can underestimate the AT intensity, since short lengths do not enable enough time for lactate transposition from cells to the bloodstream. On the other hand, long-duration stages (>5 min) will result in high blood lactate accumulation, impairing the real AT determination. Regarding the intensity, the author also suggests that if high intensity efforts were conducted (mainly in supra AT intensity stage during RLT), the subjects could reach premature exhaustion. These two concerns highlighted during the RLT should be transposed for LMT application. Despite the fact that Ribeiro et al. (2003) showed that the stage length does not influence LMI determination, we show that the length in this study was considered in terms of distance. Considering the study by Dotan (2012), future investigations should compare several LMT applications of different stage lengths with fixed time and investigate if LMI is influenced by this factor. This perspective was already explored in GXT applications and its influence was already demonstrated (Yoshida, 1984). Regarding the stage intensities, a novel investigation should be conducted by comparing two LMT applications in which stage intensities are based on AT from alternative protocols (e.g., GTX) (test 1) or based on iMLSS (test 2). Since the MLSS is the gold standard protocol for AT determination, the LMI reliability should be demonstrated in the latter test. Furthermore, in order to improve LMI precision we suggest that small intensity increments between stages (5\%) should be applied.

\section{IS THE LMI MODIFIED AFTER TRAINING?}

The relevant studies involving training effects on LMI in humans are shown in Table 2. Carter et al. (1999a) were the first to investigate the effects of training on the LMI. These authors suggested that this topic must be properly studied to prove whether the LMT is useful for longitudinal monitoring of training 
TABLE 2 | Characterization of studies with humans that investigated the effects of longitudinal training on the lactate minimum intensity (LMI).

\begin{tabular}{|c|c|c|c|c|}
\hline $\begin{array}{l}\text { Study } \\
\text { authors/country }\end{array}$ & $\begin{array}{l}\text { Study population } \\
\text { ( }{ }^{\circ} / \text { training level/ gender) }\end{array}$ & Study aim ${ }^{\S}$ & $\begin{array}{l}\text { Study results - LMI } \\
\text { before/after }\end{array}$ & Study conclusion $\S \S$ \\
\hline $\begin{array}{l}\text { Carter et al., 1999a/ } \\
\text { United Kingdom. }\end{array}$ & $\begin{array}{l}24(16 \text { completed the } \\
\text { training/ } 8 \text { acted as } \\
\text { non-training } \\
\text { control)/recreationally active } \\
(n=15) ; \text { highly trained }(n= \\
\text { 1)/13 males and } 11 \text { females. }\end{array}$ & $\begin{array}{l}\text { To investigate the LMI sensitivity } \\
\text { to six weeks of endurance } \\
\text { exercise training. }\end{array}$ & $\begin{array}{l}11.0 \pm 0.7 / 10.9 \pm 1.7 \mathrm{~km} \cdot \mathrm{h}^{-1} \\
P>0.05^{\#} ; \mathrm{SMD}-0.083\end{array}$ & $\begin{array}{l}\text { Since other parameters } \\
\text { significantly changed after the } \\
\text { training period (e.g., iMLSS), it } \\
\text { was concluded he LMl is not } \\
\text { sensitive for identifying } \\
\text { longitudinal training effects. }\end{array}$ \\
\hline $\begin{array}{l}\text { Silva et al., 2007/ } \\
\text { Brazil. }\end{array}$ & 13/soccer athletes/male. & $\begin{array}{l}\text { To investigate the effects of eight } \\
\text { weeks of soccer training on the } \\
\text { LMI. }\end{array}$ & $\begin{array}{l}14.9 \pm 0.2 / 15.4 \pm 0.4 \mathrm{~km} \cdot \mathrm{h}^{-1} \\
P<0.05^{\#} ; \mathrm{SMD}-1.667\end{array}$ & $\begin{array}{l}\text { The eight weeks of soccer } \\
\text { training resulted in positive } \\
\text { improvements of the LMI. }\end{array}$ \\
\hline $\begin{array}{l}\text { Miranda et al., 2013/ } \\
\text { Brazil. }\end{array}$ & $\begin{array}{l}\text { 13/soccer } \\
\text { athletes/non-specified. }\end{array}$ & $\begin{array}{l}\text { To investigate the effects of ten } \\
\text { weeks of soccer training on } \\
\text { several parameters (i.e. } \\
\text { anthropometric, psychological, } \\
\text { skill) including the LMI. }\end{array}$ & $\begin{array}{l}9.9 \pm 0.5 / 11.2 \pm 0.6 \mathrm{~km} . \mathrm{h}^{-1} \\
P<0.05^{\#} ; \mathrm{SMD}-2.364\end{array}$ & $\begin{array}{l}\text { The ten weeks of soccer training } \\
\text { resulted in positive improvements } \\
\text { of the several parameters } \\
\text { analyzed, including the LMI. }\end{array}$ \\
\hline $\begin{array}{l}\text { Campos et al., 2014/ } \\
\text { Brazil-Denmark. }\end{array}$ & $\begin{array}{l}\text { 8/trained swimmers/4 male } \\
\text { and } 4 \text { female. }\end{array}$ & $\begin{array}{l}\text { To investigate the effects of } \\
\text { twelve weeks of swimming } \\
\text { training on the LMI. }\end{array}$ & $\begin{array}{l}\text { Swimmers were evaluated in } \\
\text { three moments: (i) before } \\
\text { training-1.1 } \pm 0.1 \text {; (ii) after four } \\
\text { weeks-1.1 } \pm 0.1 \text {; (iii) after twelve } \\
\text { weeks-1.2 } \pm 0.1{\mathrm{~m} . \mathrm{s}^{-1}}^{-1} \\
P=0.003 \text { (i } \neq \text { ii and iii); } \\
\text { SMD-1.000. }\end{array}$ & $\begin{array}{l}\text { The LMI was partially changed } \\
\text { during the twelve weeks of } \\
\text { training, since no modification } \\
\text { was found between four and } \\
\text { twelve weeks (ii = iii). }\end{array}$ \\
\hline $\begin{array}{l}\text { Manunzio et al., 2016/ } \\
\text { Germany. }\end{array}$ & $\begin{array}{l}\text { 5/experienced cyclists and } \\
\text { triathletes }(n=4) \text { and } \\
\text { backup athlete }(n=1)\end{array}$ & $\begin{array}{l}\text { To add a detailed physiological } \\
\text { and performance profile for } \\
\text { ultra-endurance athletes over } \\
\text { their six month preparation } \\
\text { period for an 4,800 km non-stop } \\
\text { cycling race. }\end{array}$ & $\begin{array}{l}\text { Athletes were evaluated in three } \\
\text { moments in terms of LMI } \\
\text { (besides other evaluations): } \\
\text { (i) before preparation-272.0 } \pm \\
\text { 48.0; (ii) after three } \\
\text { months-282.0 } \pm 34.0 \text {; (iii) after } \\
\text { six months-292.0 } \pm 50.0 \mathrm{~W} \\
P=0.010 \text { (i } \neq \text { iii); SMD-0.408. }\end{array}$ & $\begin{array}{l}\text { LMI increased significantly over } \\
\text { the training period. }\end{array}$ \\
\hline
\end{tabular}

Note that the country was considered as the institution that authors participated in the publication year; SMD-standardized mean difference; LMI-lactate minimum intensity; iMLSS-

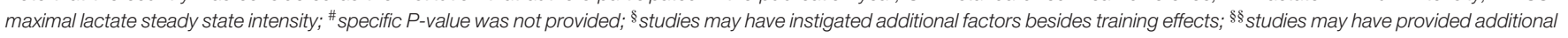
conclusions besides training effects.

effects. Thus, by evaluating sports science students, this study showed that the LMI did not change after 6 weeks of endurance training (before $-11.0 \pm 1.7$; after $-10.9 \pm 1.7 \mathrm{~km} . \mathrm{h}^{-1}$ ), despite significant improvements in $\mathrm{VO}_{2 \max }$ (before $-3.3 \pm 0.7$; after $\left.-3.6 \pm 0.81 \mathrm{~min}^{-1}\right), \mathrm{AT}_{2}$ determined during the incremental test (before $-11.2 \pm 1.8$; after $-11.9 \pm 0.8 \mathrm{~km} \cdot \mathrm{h}^{-1}$ ), iMLSS (before $-13.3 \pm 1.7$; after $-13.9 \pm 1.6 \mathrm{~km} . \mathrm{h}^{-1}$ ) among other variables. Based on these results, Carter et al. (1999a) concluded the LMT is not capable of identifying longitudinal effects of endurance training, at least when the identical LMT is applied before and after the training.

Conversely, Silva et al. (2007) showed that the LMI of elite soccer athletes significantly improved after 55 sessions (i.e., 8 weeks) of endurance, anaerobic, agility, coordination, strength and sprint training (before $-14.9 \pm 0.2$; after -15.4 $\pm 0.4 \mathrm{~km} \cdot \mathrm{h}^{-1}$ ) sessions. Even with a different initial subject training status, frequency and training load, significant LMI improvements were found for youth soccer athletes after 10 weeks (before $-9.9 \pm 0.5$; after $-11.2 \pm 0.6 \mathrm{~km} . \mathrm{h}^{-1}$ ) (Miranda et al., 2013), youth swimmers after 12 weeks (before $-1.1 \pm 0.1$; after $-1.2 \pm 0.1 \mathrm{~m} . \mathrm{s}^{-1}$ ) of training (Campos et al., 2014) and also over a 6 month preparation period of ultra endurance athletes (Manunzio et al., 2016).

Although, these results corroborate the LMT sensitivity to monitor longitudinal training effects, a limitation already addressed by Carter et al. (1999a) was highlighted. Considering the fitness improvement after the training, the intensity of the incremental stages must be modified after the training period. Otherwise the identical LMT applied after the training could underestimate the actual participant physiological condition. This will lead to a fast blood lactate removal in the first incremental stages, resulting in a left-shift of the second order polynomial fit.

This issue must be carefully investigated, since it is possible that there is a mathematical-dependency on the LMI determination and therefore its utilization for longitudinal monitoring of training effects can be dubious. Carter et al. (1999a) determined the LMI from nadir of the spline function between blood lactate and running speed. If after training there is a fast blood lactate clearance due to the fitness improvement, then 
the blood lactate concentration during the first incremental stage should be left-shifted. When the spline function is applied, the LMI is determined considering the nadir (i.e., the lowest point of the spline function). This mathematical analysis could lead to a misleading LMI determination, as it will consider the first minimum point and disregard the other points. After training, the " $U$ " shaped form and the nadir will be more pronounced, considering that more stages could be performed by subjects whether aerobic improvements are achieved during the training period or not. In addition, the stage intensity after training could not be same when compared to before. The lactate can be removed quickly (i.e., clearance), but the subject may also sustain the subsequent incremental stages producing less lactate, resulting in an aerobic improvement. In this case, a second polynomial fit should be preferred, since the LMI determination will be identified from the derived equal zero of the polynomial equation (considering all points) and therefore right-shifted.

The aforementioned hypotheses remain to be tested. Factors such as the type/load of training as well as the subject's characteristics should be taken into consideration. Some studies provided evidence that the mathematical dependency on LMI determination after some training periods may occur. For instance, improvements in terms of LMI were not observed when the spline function was applied (Carter et al., 1999a), but significant modifications of this parameter were obtained when the second order polynomial was used (Silva et al., 2007; Miranda et al., 2013). A novel study is still required to investigate whether the mathematical dependecy on LMI after training indeed exists. Such studies should consider that subjects must present improvements after the training period, otherwise the mathematical dependency could not be investigated. Along with the LMT application, we suggest that future studies also conduct the MLSS protocol to investigate whether improvements will indeed occur. Despite the fact that the experimental design of Carter et al. (1999a) covers this question, the mathematical dependecy was overlooked and our hypothesis is therefore still open for testing.

\section{DOES THE LMI INDEED ESTIMATE THE IMLSS?}

The MLSS is considered the most accurate protocol for AT determination. To precisely determine the iMLSS, at least 4-5 evaluation days are suggested (Billat et al., 2003). The myriad of definitions for iMLSS determination is also observed in scientific studies. While authors use different criteria regarding blood lactate increases (e.g., increases of 0.5 or $1.0 \mathrm{mmol.1^{-1 }}$ ) (Mocellin et al., 1990; Williams and Armstrong, 1991; Beneke and von Duvillard, 1996), others have considered different times to calculate the blood lactate increase throughout the test (Haverty et al., 1988; Aunola and Rusko, 1992; Urhausen et al., 1993). These methodological aspects were also criticized in the original LMT article (Carter et al., 1999a,b). Tegtbur et al. (1993) showed that a $0.2 \mathrm{~m} . \mathrm{s}^{-1}$ increase on the LMI was sufficient to elicit significant increases of $1.9 \pm 1.1 \mathrm{mmol}^{-1}$ in blood lactate concentration after an $8 \mathrm{~km} \cdot \mathrm{h}^{-1}$ constant run. The fact is that the $0.7 \mathrm{~km} \cdot \mathrm{h}^{-1}$ increment can be a wide intensity range and therefore provide a misleading iMLSS estimation. It is possible that the first working hypothesis of Tegtbur et al. (1993) is correct, but subsequent studies are required to properly investigate this issue.

Jones and Doust (1998) were the first to investigate this topic by comparing the LMI and the iMLSS of well-trained runners. After applying the MLSS (i.e., five constant-velocity treadmill runs of $30 \mathrm{~min}$ duration) and the original LMT, these authors observed that the LMI $\left(14.9 \pm 0.2 \mathrm{~km} \cdot \mathrm{h}^{-1}\right)$ was different $(P \leq$ $0.05)$ from the iMLSS $\left(15.7 \pm 0.3 \mathrm{~km} \cdot \mathrm{h}^{-1}\right)$ and they were poorly correlated $(r=0.61)$. The authors drew two conclusions from the results: a) future investigations should consider methodological aspects in every LMT phase, since these factors could influence the LMI determination (for complete discussion see the previous section) as well as its comparison with iMLSS; and b) according to results the LMT has poor discriminatory power between subjects, since a low relationship was observed between the LMI and iMLSS.

Two years later, Bacon and Kern (1999) insisted on studying this topic by comparing the LMI and the iMLSS of active women. These authors used similar procedures to Tegtbur et al. (1993), except for the incremental test used to induce hyperlactatemia and the smaller $0.13 \mathrm{~m} . \mathrm{s}^{-1}\left(\sim 0.5 \mathrm{~km} . \mathrm{h}^{-1}\right)$ increment above the predicted LMI during a constant velocity $28 \mathrm{~min}$ run. In addition, the definition for steady state was fixed as a blood lactate concentration less than or equal to $0.5 \mathrm{mmol} . \mathrm{l}^{-1}$ between the 4 th and 28th min. Thus, while $0.6 \pm 0.3 \mathrm{mmol} . \mathrm{l}^{-1}$ was found in the constant run at the LMI, high increases of $1.8 \pm 0.3 \mathrm{mmol}^{-1}$ were obtained in the constant run at $0.13 \mathrm{~m} . \mathrm{s}^{-1}$ above LMI. Based on the experimental procedures used, Bacon and Kern (1999) concluded that the LMI predicts the iMLSS. Such conclusions were also drawn by studies of cycling (MacIntosh et al., 2002; Knoepfli-Lenzin and Boutellier, 2011), running (Sotero et al., 2009), and swimming (Ribeiro et al., 2003) exercises.

Although, Knoepfli-Lenzin and Boutellier (2011) showed good agreement between the LMI and iMLSS (97\% inside the limits of agreement) (Bland and Altman, 1986) and high correlation ( $r=0.86)$, a slight but significant difference was also observed in cyclists $(\mathrm{LMI}=245 \pm 29$ and $\mathrm{iMLSS}=255 \pm 32 \mathrm{~W} ; P$ $\leq 0.01)$. These authors suggest this difference could be explained by the range of a $5 \mathrm{~W}$ intensity used for determining the iMLSS, which resulted in a $4 \%$ difference between the two intensities. At this point, we highlight a possible methodological concern in the iMLSS determination that could be influenced on the conclusion of the aforementioned study.

As previously noted in the beginning of this section, the myriad of MLSS applications can directly influence the iMLSS determination. Beneke (2003) suggests that the $0.5 \mathrm{mmol}^{-1}$ difference between the 10th and 20th min provides low iMLSS when compared to the $1.0 \mathrm{mmol} \cdot \mathrm{l}^{-1}$ difference between the 10th and 30th min. Although the discussion regarding the methodological aspects in the MLSS is beyond the scope of this study, we must highlight this fact since the comparison between the LMI and iMLSS could be directly influenced by this factor. This is relevant because studies that used $0.5 \mathrm{mmol} . \mathrm{l}^{-1}$ (Sotero et al., 2009) or $0.7 \mathrm{mmol}^{-1}$ (MacIntosh et al., 2002) did not observe differences between LMI and iMLSS. On the other hand, when the $1.0 \mathrm{mmol} . \mathrm{l}^{-1}$ was considered (Jones and Doust, 1998; Carter et al., 1999a; Knoepfli-Lenzin and Boutellier, 2011; Perret 
et al., 2012) the iMLSS was significant higher than the LMI (Table 3).

The comparison between these two intensities is necessary for practical applications. Additionally, the requirement of several days for the MLSS application is not welcome in current sporting calendars. Instead, the LMT could be an interesting proposal to save time. In addition, few blood collections are required during the LMT, resulting in less discomfort for the subject and improving the test objectivity. In this way, alternative LMT methods to identify the iMLSS were proposed (Pardono et al., 2008; Sotero et al., 2009). However, considering the different results among scientific studies published so far, future efforts around this issue are required. A novel study should compare the LMI and iMLSS determined within different criteria for blood lactate increase, such as $0.5,0.7$, or $1.0 \mathrm{mmol} . \mathrm{l}^{-1}$. Such designs should confirm whether this methodological aspect of the MLSS protocol influence the comparison between these two intensities.

\section{ANIMAL MODELS AND THE LMT}

Despite the fact that the LMT was originally proposed for running exercise, its application is not limited to humans. Studies successfully adapted this test for rodents (Voltarelli et al., 2002) and equines (Gondim et al., 2007). Additionally, several investigations involving animal models of different backgrounds were published. Some examples include methodological analyses (de Araujo et al., 2007; Beck et al., 2012; Sena et al., 2015), effects of periodized or non-periodized training (de Oliveira et al., 2007; de Araujo et al., 2012, 2013a, 2016; Scariot et al., 2016) effects of luminosity and time of day (Beck and Gobatto, 2013, 2016; Beck et al., 2014; Beck et al., 2014a,b) and comparion with the MLSS protocol (Rodrigues et al., 2016).

The first study that adapted the LMT for rodents was conducted by Voltarelli et al. (2002). Inside a cylinder tank (50 $\mathrm{cm}$ deep and $25 \mathrm{~cm}$ in diameter) filled with water at $31 \pm 1^{\circ} \mathrm{C}$,

TABLE 3 | Characterization of studies with humans that compared the lactate minimum intensity (LMI) with the maximal lactate steady state intensity (iMLSS).

\begin{tabular}{|c|c|c|c|c|c|}
\hline $\begin{array}{l}\text { Study } \\
\text { authors/country }\end{array}$ & $\begin{array}{l}\text { Study population } \\
\text { ( }{ }^{\circ} / \text { training } \\
\text { level/ gender) }\end{array}$ & Study $\operatorname{aim}^{\S}$ & $\begin{array}{l}\text { Exercise } \\
\text { type }\end{array}$ & Study results-LMI vs. iMLSS & Study conclusion \\
\hline $\begin{array}{l}\text { Jones and } \\
\text { Doust, } \\
\text { 1998/United } \\
\text { Kingdom. }\end{array}$ & $\begin{array}{l}\text { 13/well- } \\
\text { trained/male. }\end{array}$ & $\begin{array}{l}\text { To investigate the LMI } \\
\text { validity to estimate the } \\
\text { iMLSS. }\end{array}$ & Running & $\begin{array}{l}\text { LMI }-14.9 \pm 0.2 \mathrm{~km} \cdot \mathrm{h}^{-1} \\
\text { iMLSS }-15.7 \pm 0.3 \mathrm{~km} \cdot \mathrm{h}^{-1} \\
P<0.05^{\#} ; \text { SMD-3.200. }\end{array}$ & $\begin{array}{l}\text { Since differences were found } \\
\text { between the two intensities, it was } \\
\text { concluded that further experimental } \\
\text { investigations are required before } \\
\text { conclude the LMl estimates the } \\
\text { iMLSS. }\end{array}$ \\
\hline $\begin{array}{l}\text { Maclntosh et al., } \\
\text { 2002/Canada. }\end{array}$ & $\begin{array}{l}\text { 14/athletes- } \\
\text { cyclists or } \\
\text { triathletes/11 } \\
\text { males-3 females. }\end{array}$ & $\begin{array}{l}\text { To investigate the validity of } \\
\text { the LMI as predictor of } \\
\text { iMLSS. }\end{array}$ & Cycling & $\begin{array}{l}\text { LMI }-33.6 \pm 3.5 \mathrm{~km} \cdot \mathrm{h}^{-1} \\
\mathrm{iMLSS}-33.5 \pm 3.1 \mathrm{~km} \cdot \mathrm{h}^{-1} \\
P=0.900 ; \mathrm{SMD}-0.030\end{array}$ & $\begin{array}{l}\text { The LMI is a valid predictor of the } \\
\text { iMLSS. }\end{array}$ \\
\hline $\begin{array}{l}\text { Johnson et al., } \\
\text { 2009/United } \\
\text { Kingdom. }\end{array}$ & 32/active/male. & $\begin{array}{l}\text { To evaluate the agreement } \\
\text { between a LMI from a } \\
\text { modified LMT with the } \\
\text { iMLSS. }\end{array}$ & Cycling & $\begin{array}{l}\text { LMI }-205.0 \pm 22.0 \mathrm{~W} \\
\mathrm{iMLSS}-208.0 \pm 25.0 \mathrm{~W} \\
P \leq 0.05^{\#} ; \mathrm{SMD}-0.128\end{array}$ & $\begin{array}{l}\text { There was good agreement } \\
\text { between the LMI from a modified } \\
\text { LMT with the iMLSS. }\end{array}$ \\
\hline $\begin{array}{l}\text { Knoepfli-Lenzin } \\
\text { and Boutellier, } \\
\text { 2011/Switzerland. }\end{array}$ & $\begin{array}{l}63 / \text { moderately to } \\
\text { highly } \\
\text { trained/male. }\end{array}$ & $\begin{array}{l}\text { To investigate whether LMI } \\
\text { is valid to estimate the } \\
\text { iMLSS in subjects with } \\
\text { different levels of fitness. }\end{array}$ & Cycling & $\begin{array}{l}\text { LMI }-245.0 \pm 29.0 \mathrm{~W} \\
\text { iMLSS }-255.0 \pm 32.0 \mathrm{~W} \\
P<0.01^{\#} ; \mathrm{SMD}-0.328\end{array}$ & $\begin{array}{l}\text { Despite the significant difference } \\
\text { between the two intensities, it was } \\
\text { concluded the LMI is valid to } \\
\text { estimate the iMLSS, since the } \\
\text { difference was small and high and } \\
\text { significant relationship was found ( } r \\
\left.=0.866 ; P<0.01^{\#}\right) \text {. }\end{array}$ \\
\hline
\end{tabular}

\begin{tabular}{|c|c|c|c|}
\hline $\begin{array}{l}\text { Dotan et al., } \\
\text { 2011/Canada- } \\
\text { Israel. }\end{array}$ & $\begin{array}{l}\text { 16/trained } \\
\text { runners/male. }\end{array}$ & $\begin{array}{l}\text { To compare the LMI with } \\
\text { iMLSS and re-evaluate the } \\
\text { LMT dismissal. }\end{array}$ & Running \\
\hline
\end{tabular}

$$
\begin{aligned}
& \text { LMI was analyzed by visual } \\
& \text { inspection (LMIm) from two } \\
& \text { reviewers (mean) and } 2^{\circ} \\
& \text { polynomial fit (LMIp); } \\
& \text { LMlm - } 13.2 \pm 1.0 \mathrm{~km} \cdot \mathrm{h}^{-1} \\
& \text { LMIp - } 13.0 \pm 1.0 \mathrm{~km} \cdot \mathrm{h}^{-1} \\
& \text { iMLSS - } 13.5 \pm 0.9 \mathrm{~km} \cdot \mathrm{h}^{-1} \\
& P=\mathrm{LMIm} \text { vS. IMLSS }-0.010 \text {; } \\
& \text { LMIp vs. iMLSS }=0.001 \text {; } \\
& \text { SMD-0.441. }
\end{aligned}
$$

The LMI underestimates the iMLSS; however, the nature of this difference is still unclear and further efforts are required.

\footnotetext{
Only studies that properly applied the maximal lactate steady protocol were included. Investigations that solely investigated whether the LMI correspond to iMLSS are discussed in

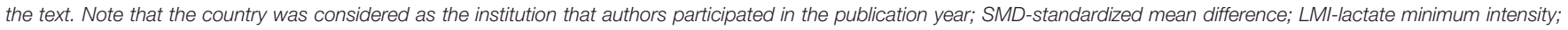
iMLSS-maximal lactate steady state intensity; " specific P-value was not provided. ${ }^{\S}$ studies may have instigated additional factors besides comparison between LMI and iMLSS.
} 
Wistar rats (Rattus norvegicus) were induced to jump into the water for $6 \mathrm{~min}$ ( $30 \mathrm{~s}$ of exercise and $30 \mathrm{~s}$ of rest) carrying loads relative to $50 \%$ of the body mass (i.e., load) on the chest to induce hyperlactatemia (phase 1). After 9 min of recovery (phase 2), the animals were submitted to an incremental swimming test (phase 3 ). The incremental test was composed of 5 min stages with loads relative to $4.5,5.0,5.5,6.0$, and $7.0 \%$ of the body mass. At the end of each stage $(30 \mathrm{~s})$, blood samples $(25 \mu \mathrm{l})$ from the distal tail were collected for the blood lactate concentration analysis. By using a spline function, these authors observed the " $U$ " shaped form proposed by Tegtbur et al. (1993), and the LMI was defined as the zero gradient tangent of the curve.

After the aforementioned study, several methodological analyses were conducted to investigate the reliability of the LMI determination in Wistar rats. For instance, the possible influence of phase 1 on the LMI determination was investigated in an animal model by de Araujo et al. (2007). Wistar rats were submitted to four similar swimming LMTs with the exception of the hyperlactatemia protocols, which were composed of different loads. These authors showed that the LMI was not significantly different from the iMLSS, independent of the hyperlactatemia protocol used. However, protocol 4 (protocol 4 consisted of a deep swim effort of $13 \%$ of the body mass and after $30 \mathrm{~s}$ of passive recovery, a second effort at the same intensity until exhaustion) was suggested, since it presented a high success rate for LMI determination ( $91 \%$ of the cases). To date, this study was the first to propose the success rate criteria for the LMI determination, which considered the presence of the " $U$ " curve (i.e., polynomial fit) followed by a $R^{2} \geq 0.80$. Regarding the mathematical models, Beck et al. (2012) found the LMI is not modified whether visual inspection, polynomial fit or spline models are used.

The LMT was also successfully applied in equines by Gondim et al. (2007). Previously the test, using five horses (Arab $n=2$; 1/2 Q.H. $n=1$; Anglo Arab $n=2$ ) ridden by their owners, was a $500 \mathrm{~m}$ full gallop on a field track $(1200 \mathrm{~m}$, grass surface) for identification of the individual time that the peak lactate concentration is attained. After $36 \mathrm{~h}$, the horses were submitted to the LMT, which was composed of the same $500 \mathrm{~m}$ full gallop to induce hyperlactatemia (phase 1), a recovery rest based on the individual time that the peak lactate concentration was attained (phase 2), and finally an incremental test was initiated at 15 $\mathrm{km} \cdot \mathrm{h}^{-1}$ with $2 \mathrm{~km} \cdot \mathrm{h}^{-1}$ increments at each $1000 \mathrm{~m}$ (phase 3). Blood samples from the jugular vein were collected at the end of the stages, and the LMI was most likely determined by visual inspection (this was not clarified in the study). After the LMT the animals were submitted to two $10000 \mathrm{~m}$ trials, and procedures that were similar to Tegtbur et al. (1993) were followed. The first trial was performed at the LMI and the second at $10 \%$ above the LMI. The authors observed that only the second trial resulted in significant lactate elevation above resting values. The authors conclude that the LMI estimates the iMLSS, but as in the original LMT study, the MLSS protocol was not properly applied. Until now, the concordance between the LMI and iMLSS in horses is not established, since two studies with different conclusions have been published on this issue so far (Miranda et al., 2014; Soares et al., 2014).
Considering the stress that several evaluation days impose on the animals, the LMT is an excellent option (Lima et al., 2017). Regarding the Wistar rats, the LMT is extensively used in different contexts as a valuable tool to estimate the aerobic capacity. In addition, authors have used the time to exhaustion (i.e., Tlim), obtained during the second swim effort at $13 \%$ of the body mass (phase 1; de Araujo et al., 2007), as an anaerobic metabolism indicator (de Araujo et al., 2012, 2013a,b). Thus, the LMT is considered a complete evaluation for Wistar rats, forasmuch as in one aerobic and anaerobic test results can be achieved. Similarly, the LMT is an excellent procedure for horses. Gondim et al. (2007) highlight that endurance horse events have been gaining popularity around the world. This fact is requiring special attention to the $\mathrm{AT}$ determination from riders, since these animals might be involuntarily submitted to high extenuating efforts, sometimes leading to fatal consequences. Thus, as a simple and inexpensive protocol, the LMT is strongly recommended for these animals.

\section{CONCLUSION}

The LMT popularity is noteworthy considering its application and data interpretation. The protocol introduced by Tegtbur et al. (1993) was recognized in the scientific community and has been extensively used in many exercises in humans and animal models. As discussed in this review, despite the LMT advantages such as time and cost saving, futures studies are required to improve the scientific knowledge around this test. Overall, this review highlighted questions that still require investigation. First, despite advances that have been made regarding methodological concerns of LMT application, several points are still missing and future studies are encouraged to deal with these questions. Second, little information was provided regarding the LMT effectiveness in identifying improvements for training. A novel investigation is required to address this issue, especially considering the possible mathematical dependency highlighted in this review. Third, efforts to prove the LMI as a valid iMLSS estimator were made; however, methodological aspects in both protocols have hampered this discussion. Further analysis to investigate these factors are worthy, since the LMT is an important physiological evaluation for cases in which exercise physiology is used.

\section{AUTHOR CONTRIBUTIONS}

LM, CG, WB, and FM contributed to the conception and design of the work, revision of the intellectual content and analysis and interpretation of the review.

\section{ACKNOWLEDGMENTS}

This review was part of a funded research project, supported by the São Paulo Research Foundation-FAPESP (Proc. 2014/10336-9) and the National Council for Scientific and Technological Development-CNPq (Proc. 442934/2014-9). 


\section{REFERENCES}

Altimari, J. M., Altimari, L. R., Gulak, A., and Chacon-Mikahil, M. P. T. (2007). Correlations between anaerobic threshold determination protocols and aerobic performance in adolescent swimmers. Rev. Bras. Med. Esporte 13, 220-226. doi: 10.1590/S1517-86922007000400007

Altimari, J. M., Chacon-Mikahil, M. P. T., Pereira, L. A., Carneiro, J. G., Cyrino, E. S., and Altimari, L. R. (2010). Lactate minimum, anaerobic threshold and critical swimming speed in boys. Braz. J. Sport Exerc. Res. 1, 25-30.

Araujo, G. G., Manchado-Gobatto, F. B., Papoti, M., Camargo, B. H. F., and Gobatto, C. A. (2013). Anaerobic and aerobic performances in elite basketball players. J. Hum. Kine 42, 137-147. doi: 10.2478/hukin-2014-0068

Aunola, S., and Rusko, H. (1992). Does anaerobic threshold correlate with maximal lactate steady-state? J. Sports Sci. 10, 309-323. doi: 10.1080/026404192087 29931

Azevedo, P. H., Drigo, A. J., Carvalho, M. C., Oliveira, J. C., Nunes, J. E., Baldissera, V., et al. (2007). Determination of judo endurance performance using the uchi - komi technique and an adapted lactate minimum test. J. Sports Sci. Med. 6, $10-14$

Bacon, L., and Kern, M. (1999). Evaluating a test protocol for predicting maximum lactate steady state. J. Sports Med. Phys. Fitness 39, 300-308.

Bang, O. (1936). The lactate content of the blood during and after muscular exercise in man. Acta Physiol. 10, 51-82. doi: 10.1111/ j.1748-1716.1936.tb00435.x

Barbieri, R. A., Barbieri, F. A., Milioni, F., Dos-Santos, J. W., Soares, M. R., Zagatto, A. M., et al. (2017). Reliability and validity of a new specific field test of aerobic capacity with the ball for futsal players. Int. J. Sports Med. 38, 233-240. doi: 10.1055/s-0042-123043

Barbieri, R. A., and Gobatto, C. A. (2013). Validation of the lactate minimum test as a specific aerobic evaluation protocol for table tennis players. J. Exerc. Physiol. Online 16, 10-20.

Bar-Or, O., Dotan, R., and Inbar, O. (1977). A 30 sec. all-out ergometer test - its reliability and validity for anaerobic capacity. Isr. J. Med. Sci. 13, 4.

Beck, W. F., De Araujo, G. G., Menezes Scariot, P. P., Masselli dos Reis, I. G., and Gobatto, C. A. (2014). Time to exhaustion at anaerobic threshold in swimming rats: metabolic investigation. Bratisl. Lek. Listy 115, 617-621. doi: 10.4149/bll_2014_119

Beck, W., and Gobatto, C. A. (2013). Effects of maximum intensity aerobic swimming exercise until exhaustion at different times of day on the hematological parameters in rats. Acta Physiol. Hung. 100, 427-434. doi: 10.1556/APhysiol.100.2013.013

Beck, W., and Gobatto, C. A. (2016). Effect of high wavelengths low intensity ligth during dark period on physical exercise performance, biochemical and haematological parameters of swimming rats. Physiol. Int. 103, 112-120. doi: 10.1556/036.103.2016.1.11

Beck, W. R., de Araujo, G. G., and Gobatto, C. A. (2012). Determination of anaerobic threshold in rats using the lactate minimum test. Comp. Exerc. Phys. 8, 113-116. doi: 10.3920/CEP12004

Beck, W. R., Ribeiro, L. F. P., Scariot, P. P. M., Reis, I. G. M., and Gobatto, C. A. (2014a). Time of day effects on aerobic capacity, muscle glycogen content and performance assessment in swimming rats. Sci. Sport 29, 319-323. doi: 10.1016/j.scispo.2014.06.005

Beck, W. R., Scariot, P. P., and Gobatto, C. A. (2014b). Primary and secondary thrombocytosis induced by exercise and environmental luminosity. Bratisl. Lek. Listy 115, 607-610. doi: 10.4149/bll_2014_117

Beneke, R. (1995). Anaerobic threshold, individual anaerobic threshold, and maximal lactate steady state in rowing. Med. Sci. Sports Exerc. 27, 863-867. doi: 10.1249/00005768-199506000-00010

Beneke, R. (2003). Methodological aspects of maximal lactate steady stateimplications for performance testing. Eur. J. Appl. Physiol. 89, 95-99. doi: 10.1007/s00421-002-0783-1

Beneke, R., Heck, H., Schwarz, V., and Leithauser, R. (1996). Maximal lactate steady state during the second decade of age. Med. Sci. Sports Exerc. 28, 1474-1478. doi: 10.1097/00005768-199612000-00006

Beneke, R., Hutler, M., and Leithauser, R. M. (2000). Maximal lactate-steady-state independent of performance. Med. Sci.
Sports Exerc. 32, 1135-1139. doi: 10.1097/00005768-20000600000016

Beneke, R., and von Duvillard, S. P. (1996). Determination of maximal lactate steady state response in selected sports events. Med. Sci. Sports Exerc. 28, 241-246. doi: 10.1097/00005768-199602000-00013

Bentley, D. J., Newell, J., and Bishop, D. (2007). Incremental exercise test design and analysis: implications for performance diagnostics in endurance athletes. Sports Med. 37, 575-586. doi: 10.2165/00007256-200737070-00002

Billat, L. V. (1996). Use of blood lactate measurements for prediction of exercise performance and for control of training. Recommendations for longdistance running. Sports Med. 22, 157-175. doi: 10.2165/00007256-19962203000003

Billat, V. L., Sirvent, P., Py, G., Koralsztein, J. P., and Mercier, J. (2003). The concept of maximal lactate steady state: a bridge between biochemistry, physiology and sport science. Sports Med. 33, 407-426. doi: 10.2165/00007256-200333060-00003

Bland, J. M., and Altman, D. G. (1986). Statistical methods for assessing agreement between two methods of clinical measurement. Lancet 1, 307-310. doi: 10.1016/S0140-6736(86)90837-8

Bosquet, L., Leger, L., and Legros, P. (2002). Methods to determine aerobic endurance. Sports Med. 32, 675-700. doi: 10.2165/00007256-200232110-00002

Brooks, G. A. (1985). Anaerobic threshold: review of the concept and directions for future research. Med. Sci. Sports Exerc. 17, 22-34. doi: 10.1249/00005768-198502000-00005

Brooks, G. A. (1986). The lactate shuttle during exercise and recovery. Med. Sci. Sports Exerc. 18, 360-368. doi: 10.1249/00005768-198606000-00019

Browne, R. A., Sales, M. M., Sotero, R. C., Asano, R. Y., Moraes, J. F. V. N., Barros, J. F., et al. (2015). Critical velocity estimates lactate minimum velocity in youth runners. Motriz 21, 1-7. doi: 10.1590/s1980-65742015000100001

Camargo, B. F., Araújo, G. G., Gobatto, C. A., Vieira, N. A., Messias, L. H. D., and Manchado-Gobatto, F. B. (2013). Adaptation of invasive and non-invasive protocols to aerobic and anaerobic specific evaluation in female basketball players. Rev. Bras. Med. Esporte 19, 171-175. doi: 10.1590/S1517-86922013000300005

Campos, E. Z., Nordsborg, N. B., Silva, A. S. R., Zagatto, A. M., Neto, J. G., Andrade, V. L., et al. (2014). The response of the lactate minimum test to a 12-week swimming training. Motriz 20, 286-291. doi: 10.1590/s1980-65742014000300007

Carter, H., Jones, A. M., and Doust, J. H. (1999a). Effect of 6 weeks of endurance training on the lactate minimum speed. J. Sports Sci. 17, 957-967. doi: $10.1080 / 026404199365353$

Carter, H., Jones, A. M., and Doust, J. H. (1999b). Effect of incremental test protocol on the lactate minimum speed. Med. Sci. Sports Exerc. 31, 837-845. doi: 10.1097/00005768-199906000-00012

Carter, H., Jones, A. M., and Doust, J. H. (2000). Changes in blood lactate and pyruvate concentrations and the lactate-to-pyruvate ratio during the lactate minimum speed test. J. Sports Sci. 18, 213-225. doi: 10.1080/026404100365117

Dantas De Luca, R., Rocha, R., Burini, R. C., Coelho Greco, C., and Denadai, B. S. (2003). The lactate minimum test protocol provides valid measures of cycle ergometer VO(2)peak. J. Sports Med. Phys. Fitness 43, 279-284.

Davis, H. A., and Gass, G. C. (1979). Blood lactate concentrations during incremental work before and after maximum exercise. Br. J. Sports Med. 13, 165-169. doi: 10.1136/bjsm.13.4.165

Davison, R. C., Swan, D., Coleman, D., and Bird, S. (2000). Correlates of simulated hill climb cycling performance. J. Sports Sci. 18, 105-110. doi: 10.1080/026404100365171

de Araujo, G. G., Papoti, M., Delbin, M. A., Zanesco, A., and Gobatto, C. A. (2013a). Physiological adaptations during endurance training below anaerobic threshold in rats. Eur. J. Appl. Physiol. 113, 1859-1870. doi: 10.1007/s00421-013-2616-9

de Araujo, G. G., Papoti, M., Dos Reis, I. G., de Mello, M. A., and Gobatto, C. A. (2012). Physiological responses during linear periodized training in rats. Eur. J. Appl. Physiol. 112, 839-852. doi: 10.1007/s00421-011-2020-2

de Araujo, G. G., Papoti, M., Manchado Fde, B., de Mello, M. A., and Gobatto, C. A. (2007). Protocols for hyperlactatemia induction in the lactate minimum test adapted to swimming rats. Comp. Biochem. Physiol. Part A Mol. Integr. Physiol. 148, 888-892. doi: 10.1016/j.cbpa.2007.09.002 
de Araujo, G. G., Papoti, M., Manchado-Gobatto Fde, B., de Mello, M. A., and Gobatto, C. A. (2013b). Monitoring chronic physical stress using biomarkers, performance protocols and mathematical functions to identify physiological adaptations in rats. Lab. Anim. 47, 36-42. doi: 10.1177/0023677212473715

de Araujo, G. G., Papoti, M., dos Reis, I. G. M., de Mello, M. A. R., and Gobatto, C. A. (2016). Short and long term effects of high-intensity interval training on hormones, metabolites, antioxidant system, glycogen concentration, and aerobic performance adaptations in rats. Front. Physiol. 7:505. doi: 10.3389/fphys.2016.00505

Denadai, B. S., and Higino, W. P. (2004). Effect of the passive recovery period on the lactate minimum speed in sprinters and endurance runners. J. Sci. Med. Sport 7, 488-496. doi: 10.1016/S1440-2440(04)80268-8

de Oliveira, C. A., Luciano, E., Marcondes, M. C., and de Mello, M. A. (2007). Effects of swimming training at the intensity equivalent to aerobic/anaerobic metabolic transition in alloxan diabetic rats. J. Diabetes Complications 21, 258-264. doi: 10.1016/j.jdiacomp.2006.07.007

Donovan, C. M., and Brooks, G. A. (1983). Endurance training affects lactate clearance, not lactate production. Am. J. Physiol. 244, E83-E92.

Dotan, R. (2012). Reverse lactate threshold: a novel single-session approach to reliable high-resolution estimation of the anaerobic threshold. Int. J. Sports Physiol. Perform. 7, 141-151. doi: 10.1123/ijspp.7.2.141

Dotan, R., Zigel, L., Rotstein, A., Greenberg, T., Benyamini, Y., and Falk, B. (2011). Reliability and validity of the lactate-minimum test. A revisit. J. Sports Med. Phys. Fitness 51, 42-49.

Gaesser, G. A., and Brooks, G. A. (1984). Metabolic bases of excess postexercise oxygen consumption: a review. Med. Sci. Sports Exerc. 16, 29-43. doi: 10.1249/00005768-198401000-00008

Gladden, L. B. (2008). 200th anniversary of lactate research in muscle. Exerc. Sport Sci. Rev. 36, 109-115. doi: 10.1097/JES.0b013e31817c0038

Glenn, T. C., Martin, N. A., Horning, M. A., McArthur, D. L., Hovda, D. A., Vespa, P., et al. (2015). Lactate: brain fuel in human traumatic brain injury: a comparison with normal healthy control subjects. J. Neurotrauma 32, 820-832. doi: 10.1089/neu.2014.3483

Gobatto, C. A., de Mello, M. A., Sibuya, C. Y., de Azevedo, J. R., dos Santos, L. A., and Kokubun, E. (2001). Maximal lactate steady state in rats submitted to swimming exercise. Comp. Biochem. Physiol. Part A Mol. Integr. Physiol. 130, 21-27. doi: 10.1016/S1095-6433(01)00362-2

Gondim, F. J., Zoppi, C. C., Pereira-da-Silva, L., and de Macedo, D. V. (2007). Determination of the anaerobic threshold and maximal lactate steady state speed in equines using the lactate minimum speed protocol. Comp. Biochem. Physiol. Part A Mol. Integr. Physiol. 146, 375-380. doi: 10.1016/j.cbpa.2006.11.002

Halestrap, A. P. (2013). Monocarboxylic acid transport. Compr. Physiol. 3, 1611-1643. doi: 10.1002/cphy.c130008

Haverty, M., Kenney, W. L., and Hodgson, J. L. (1988). Lactate and gas exchange responses to incremental and steady state running. Br. J. Sports Med. 22, 51-54. doi: 10.1136/bjsm.22.2.51

Heck, H., Mader, A., Hess, G., Mucke, S., Muller, R., and Hollmann, W. (1985). Justification of the 4-mmol/l lactate threshold. Int. J. Sports Med. 6, 117-130. doi: 10.1055/s-2008-1025824

Hill, A. V., and Lupton, H. (1923). Muscular exercise, lactic acid, and the supply and utilization of oxygen. QJM 16, 135-171. doi: 10.1093/qjmed/os-16.62.135

Hinkley, D. V. (1969). Inference about the intersection in two-phase regression. Biometrika 56, 495-504. doi: 10.1093/biomet/56.3.495

Hiyane, W. C., Simões, H. G., and Campbell, C. S. (2006). Critical velocity as a noninvasive method to estimate the lactate minimum velocity on cycling. Rev. Bras. Med. Esporte 12, 340-344. doi: 10.1590/S1517-86922006000600016

Hollmann, W. (1959). The Relationship between pH, Lactic Acid, Potassium in the Arterial and Venous Blood, The Ventilation, PoW and Pulse Frequency during Increasing Spiro-Ergometric Work in Endurance- Trained and Untrained Persons. Chicago: Panamerican Congress for Sportsmedicine.

Johnson, M. A., and Sharpe, G. R. (2011). Effects of protocol design on lactate minimum power. Int. J. Sports Med. 32, 199-204. doi: 10.1055/s-0030-1268487

Johnson, M. A., Sharpe, G. R., and Brown, P. I. (2009). Investigations of the lactate minimum test. Int. J. Sports Med. 30, 448-454. doi: 10.1055/s-0028-1119404

Jones, A. M., and Carter, H. (2000). The effect of endurance training on parameters of aerobic fitness. Sports Med. 29, 373-386. doi: 10.2165/00007256-200029060-00001
Jones, A. M., and Doust, J. H. (1998). The validity of the lactate minimum test for determination of the maximal lactate steady state. Med. Sci. Sports Exerc. 30, 1304-1313. doi: 10.1097/00005768-199808000-00020

Jones, A. M., Vanhatalo, A., Burnley, M., Morton, R. H., and Poole, D. C. (2010). Critical power: implications for determination of $\mathrm{V}$ O2max and exercise tolerance. Med. Sci. Sports Exerc. 42, 1876-1890. doi: 10.1249/MSS.0b013e3181d9cf7f

Juel, C., and Halestrap, A. P. (1999). Lactate transport in skeletal muscle - role and regulation of the monocarboxylate transporter. J. Physiol. 517(Pt 3), 633-642. doi: 10.1111/j.1469-7793.1999.0633s.x

Karvonen, J., and Vuorimaa, T. (1988). Heart rate and exercise intensity during sports activities. Pract. Appl. Sports Med. 5, 303-311. doi: 10.2165/00007256-198805050-00002

Kindermann, W., Simon, G., and Keul, J. (1979). The significance of the aerobic-anaerobic transition for the determination of work load intensities during endurance training. Eur. J. Appl. Physiol. Occup. Physiol. 42, 25-34. doi: 10.1007/BF00421101

Kirkham, A. A., Campbell, K. L., and McKenzie, D. C. (2013). Comparison of aerobic exercise intensity prescription methods in breast cancer. Med. Sci. Sports Exerc. 45, 1443-1450. doi: 10.1249/MSS.0b013e3182895195

Klika, R. J., Callahan, K. E., and Drum, S. N. (2009). Individualized 12-week exercise training programs enhance aerobic capacity of cancer survivors. Phys. Sportsmed. 37, 68-77. doi: 10.3810/psm.2009.10.1731

Knoepfli-Lenzin, C., and Boutellier, U. (2011). Lactate minimum is valid to estimate maximal lactate steady state in moderately and highly trained subjects. J. Strength Cond. Res. 25, 1355-1359. doi: 10.1519/JSC.0b013e3181d6dbf4

Lima, A. A., Gobatto, C. A., Messias, L. H. D., Scariot, P. P. M., Forte, L. D. M., Santin, J. O., et al. (2017). Two water enviroment adaptation models enchace motor behavior and improve the success of the lactate minimum test in swimming rats. Motriz 23, e101607. doi: 10.1590/s1980-6574201700si0009

MacIntosh, B. R., Esau, S., and Svedahl, K. (2002). The lactate minimum test for cycling: estimation of the maximal lactate steady state. Can. J. Appl. Physiol. 27, 232-249. doi: 10.1139/h02-014

Mader, A., and Heck, H. (1986). A theory of the metabolic origin of "anaerobic threshold”. Int. J. Sports Med. 7(Suppl. 1), 45-65. doi: 10.1055/s-2008-1025802

Manunzio, C., Mester, J., Kaiser, W., and Wahl, P. (2016). Training intensity distribution and changes in performance and physiology of a 2nd place finisher team of the race across america over a 6 month preparation period. Front. Physiol. 7:642. doi: 10.3389/fphys.2016.00642

Margaria, R., Edwards, H. T., and Dill, D. B. (1933). The possible mechanisms of contracting and paying the oxygen debt and the role of lactic acid in muscular contraction. Am. J. Physiol. 106, 689-715.

Mendes, R., Sousa, N., Almeida, A., Subtil, P., Guedes-Marques, F., Reis, V. M., et al. (2015). Exercise prescription for patients with type 2 diabetes-a synthesis of international recommendations: narrative review. Br. J. Sports Med. 50, 1379-1381. doi: 10.1136/bjsports-2015-094895

Messias, L. H. D., Andrade, V. C., Rosante, K. T., Lima, T. B., Cruz, R. A. S., Oliviera, R. M., et al. (2015). Running anaerobic sprint test, lactate minimum and critical velocity protocol in shutlle futsal testing. Central Eur. J. Sport Sci. Med. 12, 5-15. doi: 10.18276/cej.2015.4-01

Mezzaroba, P. V., and Machado, F. A. (2013). Indirect determination of lactate minimum speed from a single maximal performance in young swimmers. $J$. Sports Sci. Med. 12, 655-659.

Miranda, M. C., Queiroz-Neto, A., Silva-Junior, J. R., Pereira, M. C., Soares, O. A., Borghi, R. T., et al. (2014). Comparison of the lactate minimum speed and the maximal lactate steady state to determine aerobic capacity in purebred Arabian horses. N. Z. Vet. J. 62, 15-20. doi: 10.1080/00480169.2013.815103

Miranda, R. E. E. P. C., Antunes, H. K. M., Pauli, J. R., Puggina, E. F., and da Silva, A. S. R. (2013). Effects of 10-week soccer training program on anthropometric, psychological, technical skills and specific performance parameters in youth soccer players. Sci. Sport 28, 81-87. doi: 10.1016/j.scispo.2012. 02.005

Miyagi, W. E., Leite, J. V. M., and Zagatto, A. M. (2013). Influence of the selection from incremental stages on lactate minimum intensity: a pilot study. Braz. J. K. Hum. Perf. 15, 715-725. doi: 10.5007/1980-0037.2013v15n6p715

Miyagi, W. E., Malta Ede, S., and Zagatto, A. M. (2015). Maximal oxygen uptake cannot be determined in the incremental phase of the lactate minimum test on a cycle ergometer. J. Sports Sci. Med. 14, 372-378. 
Mocellin, R., Heusgen, M., and Korsten-Reck, U. (1990). Maximal steady state blood lactate levels in 11-year-old boys. Eur. J. Pediatr. 149, 771-773. doi: $10.1007 /$ BF01957277

Monod, H., and Scherrer, J. (1965). The work capacity of a synergic muscular group. Ergonomics 8:10. doi: 10.1080/00140136508930810

Moritani, T., Nagata, A., deVries, H. A., and Muro, M. (1981). Critical power as a measure of physical work capacity and anaerobic threshold. Ergonomics 24, 339-350. doi: 10.1080/00140138108924856

Mosso, A. (1904). Fatigue. New York, NY: G.P. Putnam's Sons; London: S. Sonnenschein.

Mota, G. R., Magalhães, C. G., Azevedo, P. H. S. M., Ide, B. N., Lopes, C. R., Castardeli, E., et al. (2011). Lactate threshold in taekwondo through specifics tests. J. Exerc. Physiol. Online 14, 60-66.

O'Hagan, C., De Vito, G., and Boreham, C. A. (2013). Exercise prescription in the treatment of type 2 diabetes mellitus: current practices, existing guidelines and future directions. Sports Med. 43, 39-49. doi: 10.1007/s40279-012-0004-y

Oliveira, C. A., Paiva, M. F., Mota, C. A., Ribeiro, C., Leme, J. A., Luciano, E., et al. (2010). Exercise at anaerobic threshold intensity and insulin secretion by isolated pancreatic islets of rats. Islets 2, 240-246. doi: 10.4161/isl.2.4. 12266

Paffenbarger, R. S. Jr., and Hyde, R. T. (1984). Exercise in the prevention of coronary heart disease. Prev. Med. 13, 3-22. doi: 10.1016/0091-7435(84)90037-9

Pardono, E., Sotero Rda, C., Hiyane, W., Mota, M. R., Campbell, C. S., Nakamura, F. Y., et al. (2008). Maximal lactate steady-state prediction through quadratic modeling of selected stages of the lactate minimum test. J. Strength Cond. Res. 22, 1073-1080. doi: 10.1519/JSC.0b013e318173c594

Parmenter, B. J., Dieberg, G., and Smart, N. A. (2015). Exercise training for management of peripheral arterial disease: a systematic review and meta-analysis. Sports Med. 45, 231-244. doi: 10.1007/s40279-0140261-z

Perret, C., Labruyere, R., Mueller, G., and Strupler, M. (2012). Correlation of heart rate at lactate minimum and maximal lactate steady state in wheelchair-racing athletes. Spinal Cord 50, 33-36. doi: 10.1038/sc.2011.97

Poole, D. C., and Richardson, R. S. (1997). Determinants of oxygen uptake. Implications Exerc. Test. Sports Med. 24, 308-320. doi: 10.2165/00007256-199724050-00003

Poole, D. C., Ward, S. A., Gardner, G. W., and Whipp, B. J. (1988). Metabolic and respiratory profile of the upper limit for prolonged exercise in man. Ergonomics 31, 1265-1279. doi: 10.1080/00140138808966766

Ribeiro, L., Balikian, P., Malachias, P., and Baldissera, V. (2003). Stage length, spline function and lactate minimum swimming speed. J. Sports Med. Phys. Fitness 43, 312-318.

Ribeiro, L. F., Goncalves, C. G., Kater, D. P., Lima, M. C., and Gobatto, C. A. (2009). Influence of recovery manipulation after hyperlactemia induction on the lactate minimum intensity. Eur. J. Appl. Physiol. 105, 159-165. doi: 10.1007/s00421-008-0885-5

Rodrigues, N. A., Torsoni, A. S., Fante, T., dos Reis, I. G. M., Gobatto, C. A., and Manchado-Gobatto, F. B. (2016). Lactate minimum underestimates the maximal lactate steady-state in swimming mice. Appl. Physiol. Nutr. Metab. 42, 46-52. doi: 10.1139/apnm-2016-0198

Rotstein, A., Dotan, R., Zigel, L., Greenberg, T., Benyamini, Y., and Falk, B. (2007). The effect of pre-test carbohydrate ingestion on the anaerobic threshold, as determined by the lactate-minimum test. Appl. Physiol. Nutr. Metab. 32, 1058-1064. doi: 10.1139/H07-066

Scariot, P. P., Manchado-Gobatto Fde, B., Torsoni, A. S., Dos Reis, I. G., Beck, W. R., and Gobatto, C. A. (2016). Continuous aerobic training in individualized intensity avoids spontaneous physical activity decline and improves MCT1 expression in oxidative muscle of swimming rats. Front. Physiol. 7:132. doi: 10.3389/fphys.2016.00132

Scharhag-Rosenberger, F., Kuehl, R., Klassen, O., Schommer, K., Schmidt, M. E., Ulrich, C. M., et al. (2015). Exercise training intensity prescription in breast cancer survivors: validity of current practice and specific recommendations. J. Cancer Surviv. 9, 612-619. doi: 10.1007/s11764-015-0437-z

Sena, M. S., Junior, R. C. V., Rubim, C. C., Lima, T. R., Trombeta, J. C. S., Garcia, A., et al. (2015). Blood lactate minimum of rats during swimming test using three incremental stages. Motriz 21, 290-298. doi: $10.1590 /$ s1980-65742015000300010
Silva, A. S. R., Bonette, A. L., Santhiago, V., and Gobatto, C. A. (2007). Effect of soccer training on the running speed and the blood lactate concentration at the lactate minimum test. Biol. Sport 24, 105-114.

Simões, H. G., Denadai, B. S., Baldissera, V., Campbell, C. S., and Hill, D. W. (2005). Relationships and significance of lactate minimum, critical velocity, heart rate deflection and $3000 \mathrm{~m}$ track-tests for running. J. Sports Med. Phys. Fitness 45, 441-451.

Simões, H. G., Hiyane, W. C., Sotero, R. C., Pardono, E., Puga, G. M., Lima, L. C., et al. (2009). Polynomial modeling for the identification of lactate minimum velocity by different methods. J. Sports Med. Phys. Fitness 49, $14-18$.

Sjodin, B., and Jacobs, I. (1981). Onset of blood lactate accumulation and marathon running performance. Int. J. Sports Med. 2, 23-26. doi: 10.1055/s-20081034579

Smith, M. F., Balmer, J., Coleman, D. A., Bird, S. R., and Davison, R. C. (2002). Method of lactate elevation does not affect the determination of the lactate minimum. Med. Sci. Sports Exerc. 34, 1744-1749. doi: 10.1097/00005768-200211000-00009

Soares, O. A. B., Ferraz, G. C., Martins, C. B., Dias, D. P. M., Lacerda-Neto, J. C., and Queiroz-Neto, A. (2014). Comparison of maximal lactate steady state with V2, V4, individual anaerobic threshold and lactate minimum speed in horses. Arq. Bras. Med. Vet. Zootec 66, 39-46. doi: 10.1590/S0102-093520140001 00007

Sotero, R. C., Campbell, C. S., Pardono, E., Puga, G. M., and Simões, H. G. (2007). Polynomial adjustment as a new technique for determination of lactate minimum velocity with blood sampling reduction. Braz. J. K. Hum. Perf. 9, 327-332.

Sotero, R. C., Cunha, V. N. C., Madrid, B., Sales, M. M., Moreira, S. R., and Simões, H. G. (2011). Lactate minimum identification in youth runners through a track test of three incremental stages. Rev. Bras. Med. Esporte 17, 119-122. doi: 10.1590/S1517-86922011000200010

Sotero, R. C., Pardono, E., Landwehr, R., Campbell, C. S., and Simões, H. G. (2009). Blood glucose minimum predicts maximal lactate steady state on running. Int. J. Sports Med. 30, 643-646. doi: 10.1055/s-0029-12 20729

Sousa, F. A. B., Rodrigues, N. A., Messias, L. H. D., Queiroz, J. B., ManchadoGobatto, F. B., and Gobatto, C. A. (2017). Aerobic and anerobic swimming force evaluation in one single test session for young swimmers. Int. J. Sports Med. 38, 378-383. doi: 10.1055/s-0043-100101

Stegmann, H., Kindermann, W., and Schnabel, A. (1981). Lactate kinetics and individual anaerobic threshold. Int. J. Sports Med. 2, 160-165. doi: $10.1055 / \mathrm{s}-2008-1034604$

Tegtbur, U., Busse, M. W., and Braumann, K. M. (1993). Estimation of an individual equilibrium between lactate production and catabolism during exercise. Med. Sci. Sports Exerc. 25, 620-627. doi: 10.1249/00005768-199305000-00015

Thomas, C., Bishop, D. J., Lambert, K., Mercier, J., and Brooks, G. A. (2012). Effects of acute and chronic exercise on sarcolemmal MCT1 and MCT4 contents in human skeletal muscles: current status. Am. J. Physiol. Regul. Integr. Comp. Physiol. 302, R1-R14. doi: 10.1152/ajpregu.002 50.2011

Urhausen, A., Coen, B., Weiler, B., and Kindermann, W. (1993). Individual anaerobic threshold and maximum lactate steady state. Int. J. Sports Med. 14, 134-139. doi: 10.1055/s-2007-1021157

Vicente-Campous, D., Barbado, C., Nunez, M. J., and Chicharro, J. L. (2014). Lactate minimum test during incremental running after a submaximal cycling exercise: a novel test with training applications for triathletes. J. Sports Med. Phys. Fitness 54, 742-749.

Voltarelli, F. A., Gobatto, C. A., and Mello, M. A. R. (2002). Determination of anaerobic threshold in rats using the lactate minimum test. Braz. J. Med. Biol. Resea 35, 1389-1394. doi: 10.1590/S0100-879X20020011 00018

Wasserman, K., and McIlroy, M. B. (1964). Detecting the Threshold of Anaerobic Metabolism in Cardiac Patients during Exercise. Am. J. Cardiol. 14, 844-852. doi: 10.1016/0002-9149(64)90012-8

Williams, J. R., and Armstrong, N. (1991). Relationship of maximal lactate steadystate to performance at fixed blood lactate reference values in children. Ped. Exerc. Sci. 3, 333-341. doi: 10.1123/pes.3.4.333 
Yoshida, T. (1984). Effect of exercise duration during incremental exercise on the determination of anaerobic threshold and the onset of blood lactate accumulation. Eur. J. Appl. Physiol. Occup. Physiol. 53, 196-199. doi: 10.1007/BF00776589

Zacharogiannis, E., Paradisis, G., and Tziortzis, S. (2004). "An evaluation of tests of anaerobic power and capacity," in Annual Meeting of the American College of Sports Medicine, Indianapolis. (Accession No.: 00005768-200405001-00549).

Zagatto, A. M., Miyagi, W. E., Sakugawa, R. L., and Papoti, M. (2013). Use of maximal running distance performed on hoff test for anaerobic threshold prediction in soccer. Rev. Bras. Med. Esporte 19, 267-270. doi: 10.1590/S1517-86922013000400008

Zagatto, A. M., Padulo, J., Muller, P. T., Miyagi, W. E., Malta, E. S., and Papoti, M. (2014). Hyperlactemia induction modes affect the lactate minimum power and physiological responses in cycling. J. Strength Cond. Res. 28, 2927-2934. doi: 10.1519/JSC.0000000000000490

Zagatto, A. M., Papoti, M., Caputo, F., Mendes, O. C., Denadai, B. S., Baldissera, V., et al. (2004). Comparison between the use of saliva and blood for the minimum lactate determination in arm ergometer and cycle ergometer in table tennis players. Rev. Bras. Med. Esporte 10, 481-486. doi: $10.1590 /$ S1517-86922004000600004

Conflict of Interest Statement: The authors declare that the research was conducted in the absence of any commercial or financial relationships that could be construed as a potential conflict of interest.

The reviewer FRS and handling Editor declared their shared affiliation, and the handling Editor states that the process nevertheless met the standards of a fair and objective review.

Copyright (c) 2017 Messias, Gobatto, Beck and Manchado-Gobatto. This is an openaccess article distributed under the terms of the Creative Commons Attribution License (CC BY). The use, distribution or reproduction in other forums is permitted, provided the original author(s) or licensor are credited and that the original publication in this journal is cited, in accordance with accepted academic practice. No use, distribution or reproduction is permitted which does not comply with these terms. 